\title{
Thermal analysis in a triple-layered skin structure with embedded vasculature, tumor, and gold nanoshells
}

\author{
Casey Orndorff ${ }^{\mathrm{a}}$, Stanislav Ponomarev ${ }^{\mathrm{a}}$, Weizhong Dai ${ }^{\mathrm{a}, *}$, Adrian Bejan ${ }^{\mathrm{b}}$ \\ a Mathematics \& Statistics, College of Engineering E Science, Louisiana Tech University, Ruston, LA 71272, USA \\ ${ }^{\mathrm{b}}$ Department of Mechanical Engineering and Materials Science, Duke University, Durham, NC 27708, USA
}

\section{A R T I C L E I N F O}

\section{Article history:}

Received 14 December 2016

Received in revised form 5 March 2017

Accepted 7 April 2017

\section{Keywords:}

Constructal law

Skin

Finite-difference method

Thermal analysis

Vascular network

Golden nanoshells

\begin{abstract}
A B S T R A C T
Obtaining accurate temperature distributions in living tissue related to hyperthermia skin cancer treatment without using an intruding sensor is a challenge. Here, we report a mathematical model that can accurately determine the temperature distribution in the tumor region and surrounding normal tissue. The model is based on a modified Pennes' equation for the bioheat transfer in a 3-D triple-layered skin structure embedded with a vascular countercurrent network and a tumor appearing in the subcutaneous region. The vascular network is designed based on the constructal theory of multi-scale tree-shaped heat exchangers. The tumor is injected with gold nanoshells in order to be heated quickly. The proposed model is implemented numerically using a stable finite difference scheme. The method is demonstrated and tested by an example.
\end{abstract}

(c) 2017 Elsevier Ltd. All rights reserved.

\section{Introduction}

In hyperthermia skin cancer treatment, the objective is the control laser heating of the tumor (target temperatures of $42-46{ }^{\circ} \mathrm{C}$ ) so that the temperatures of the normal tissue surrounding the tumor remains low enough not to damage the normal tissue. However, it is not easy to obtain an accurate determination of the temperature field over the entire treatment region during clinical hyperthermia treatments, because the number of invasive temperature probes that can be used is limited due to the pain tolerances of the patients. Hence, it is important to determine the laser intensity and pattern of laser exposure for optimizing the temperature distribution in the treated region. The determinants of temperature distributions during thermal therapy include the power deposition pattern of the heating source, heat removal by conduction, and heat removal by blood flow forced convection.

There are many numerical and experimental methods developed based on the Pennes' bioheat transfer equation [1-22]. Among these, Liauh and Roemer [2] presented a semi-linear state and parameter estimation algorithm that decreases the total computational time between the temperature and the blood perfusion based on the Pennes' bioheat transfer equation (BHTE) in the hyperthermia temperature estimation problem. Huang [4] considered

\footnotetext{
* Corresponding author.

E-mail address: dai@coes.latech.edu (W. Dai).
}

the heat transfer within a perfused tissue in the presence of a vessel. Payne [6] designed a phantom from the combination of the convective fin equation and the Pennes' BHTE, and developed a phantom model using an inverse technique applied to experimental data from a thin layer phantom to determine model parameters. Liu $[8,9]$ modeled wave-like behaviors of bioheat transfer in a 1-D triple-layered skin structure which was solved by using a finite difference method. Sun et al. [10] developed a system that can treat tumor tissue and monitor the heating and cooling during the treatment by means of an invasive probe. The prediction of the temperature distribution in the tumor was modeled using the Pennes' equation. Dai and his colleagues [11-13] developed a domain decomposition method for solving the 3-D Pennes' BHTE in a triple-layered skin structure. In particular, Zeng et al. [14] developed a model for a 3-D triple-layered skin structure with a vascular countercurrent network that employed a modified Pennes' equation which accounts for thermal lag of the tissue where the vascular network is designed based on the constructal theory of multi-scale tree-shaped heat exchangers. Majchrzak and colleagues [15] developed a model based on the Pennes' equation to study the hyperthermia and hypothermia processes and to identify thermal parameters in a biological medium. Jamil and $\mathrm{Ng}$ [16] developed a model that predicts the leading factor for hyperthermia treatment using electromagnetic radiation in a single-layered human tissue structure with an embedded tumor based on the Pennes' equation. Randrianalisoa et al. [18] investigated effects of 
short-pulsed laser radiation transient heating of superficial human tissues. Majchrzak [19] modeled the dual-phase lag equation in a 3-D skin structure and obtained a solution numerically with an explicit finite difference method. Kumar and Srivastava [20] numerically investigated the influence of pulsatile blood flow on temperature distribution within the body of laser-irradiated biological tissue phantoms.

For hyperthermia cancer treatment, a recent advance is to inject golden nanoparticles into the tumor region in order to heat it up quickly [23-36]. Bayazitoglu and her colleagues [23-25] developed a model that used the finite difference time domain (FDTD) to calculate the heat distribution of nanoshells on a single layer of human biological tissue at varying particle distribution densities in different host mediums. Recently, they [26-28] have extended their study to the modeling and numerical investigation of nanoparticle assisted laser-induced thermotherapy for tumor and cancer treatments. Cai et al. [29] discussed the applications of gold nanoparticles in cancer nanotechnology. Pignol et al. [30] used the Monte Carlo method to predict gold nanoparticle radiosensitization needed to be lethal in a cell media on the nanoscale. Singh et al. [31] numerically studied the laser-induced hyperthermia of nanoshell mediated vascularized tissue. Lin et al. [32] also used the Monte Carlo method to model the effect of gold nanoparticles in response to multiple beam intensities to enhance the effect of proton beam therapy. Zunino et al. [33] developed a model that predicts the effect of nanoparticles in a tumor microenvironment in the form of temperature, by using the finite element method while taking into account the tumor's vascular system and heat transfer of the vascular system with the distribution of nanoparticles. Sazgarnia et al. [34] developed a model with gold nanoshells to predict the temperature distribution of a prostate with a tumor irradiated by a laser, which was solved numerically by the finite element method. Liu et al. [35] presented nanoscale optomechanical actuators for controlling mechanotransduction in living cells. Frieboes and Curtis et al. [36] evaluated the effects of drugloaded gold nanoparticles in highly vascularized tumors, where the effect of the nanoparticles decreased tumor size in comparison to drug-free nanoparticles.

Up to date, modeling the laser heating in a 3-D triple-layered skin tissue where the tumor is injected by nanoparticles with a nearby countercurrent vascular network has not been seen. For this purpose, the present study develops a mathematical model that can accurately determine the temperature in the tumor region and surrounding normal tissue. Our model is based on a modified Pennes' equation for the bioheat transfer in a 3-D triple-layered skin structure embedded with a vascular countercurrent network and a tumor appearing in the subcutaneous region. The vascular network is designed based on the constructal theory of multiscale tree-shaped heat exchangers. The tumor is injected with golden nanoshells in order to be heated quickly. The proposed model is then solved numerically using a stable finite-difference scheme. Such research may provide an useful tool for optimizing laser irradiation to kill the tumor while keeping the damage to the surrounding healthy tissue to a minimum during the hyperthermia cancer treatment. Our preliminary idea and outline for this study with not yet obtaining numerical results was presented in the 2015 Constructal Law Conference held in Italy in May 2015 and was included in the conference proceedings, which appeared in a special issue in International Journal of Heat and Technology [37]. The present article not only improves the model by considering the thermal lag of heat flux on the skin surface and a different thermal lag in the tumor than in the healthy tissue, but also completes the study with computational procedure and numerical results.

The organization of the rest of the text is given as follows. In Section 2, the bioheat transfer model for thermal analysis in a
3-D triple-layered skin structure with a countercurrent vascular network with an embedded tumor and nanoshells in the subcutaneous region is presented. In Section 3, we propose a finite difference method and computational procedure for solving the model. In Section 4, we test the method by an example.

\section{Mathematical model}

\subsection{Network design}

For simplicity, we consider the skin tissue to be a rectangular structure embedded with a seven-level countercurrent vascular network, which is a highly branching and hierarchical network as described in [38], under the tumor region in the subcutaneous layer. The tumor region is assumed to locate directly below the dermis layer, as shown in Fig. 1. It should be pointed out that only large blood vessels can be seen in the subcutaneous tissue because the significance of the blood vessel in light propagation is dependent on the relative diameter of the blood vessel to the mean free path (MFP, i.e., the reciprocal of the total attenuate coefficient of light in tissue) of photon in tissues. If the vessel diameter is much less than the photon MFP, the contribution of these vessels to the light distributed can be collectively represented by a continuum model [40]. Therefore, we combine the tissue and capillary blood vessels together and use one heat transfer equation for both the capillary beds and tissue. Furthermore, the dermis is very sparingly supplied with capillaries and the capillary beds of skin lying immediately below the epidermis, and thus, the contribution of these small vessels to the heat transfer can be ignored $[39,40]$. In Fig. 1 , the red $^{1}$ color dendritic network represents arteries while the blue color dendritic network represents veins, where all are considered as slender cuboids for simplicity. Levels of arteries are designed such that the first-level artery runs from right to left along the $x$-coordinate; the second-level artery branches from the left end of the first-level artery and flows along the $y$-coordinate; the thirdlevel artery has two vessels branching from the two ends of the second-level artery, and flowing along the $z$-coordinate; there are four fourth-level arteries branching from the four ends of the third-level arteries, which flow along the $x$-coordinate; the fifthlevel artery has eight arteries branching from the eight ends of the fourth-level arteries, and so on. The vein network has the same number of blood vessels as its counterpart artery in corresponding levels.

In sum, there are 128 blood vessels in total in the considered skin structure. Although the orthogonal structure of blood vessels (Fig. 1) is a special design, the constructal-design literature has shown convincingly $[41,42]$ that when the complexity of the tree is as high as in the present model, the volume averaged flow perfusion properties (such as the permeability) do not change if the details of the tree architecture change. The tree flow architecture is robust, and this is why the use of assumed structures in the numerical modeling of previously untractable 'complex' flow structure has a real opportunity for advances.

To determine the diameters of the blood vessels on each level, we follow the constructal theory of multi-scale tree-shaped heat exchangers [41-44] and assume that the diameters of arteries are decreasing by a constant ratio $\gamma$ between successive levels of branched vessels, given by [44],

$\gamma=\frac{N L_{b}^{m+1}}{N L_{b}^{m}}=\frac{N W_{b}^{m+1}}{N W_{b}^{m}}=2^{-\frac{1}{3}}, \quad m=1, \ldots, 6$,

where $N L_{b}^{m}$ and $N W_{b}^{m}$ are the length and width of the cross section of a blood vessel in level $m$, respectively. The length of a blood vessel is

\footnotetext{
${ }^{1}$ For interpretation of color in Fig. 1, the reader is referred to the web version of this article.
} 


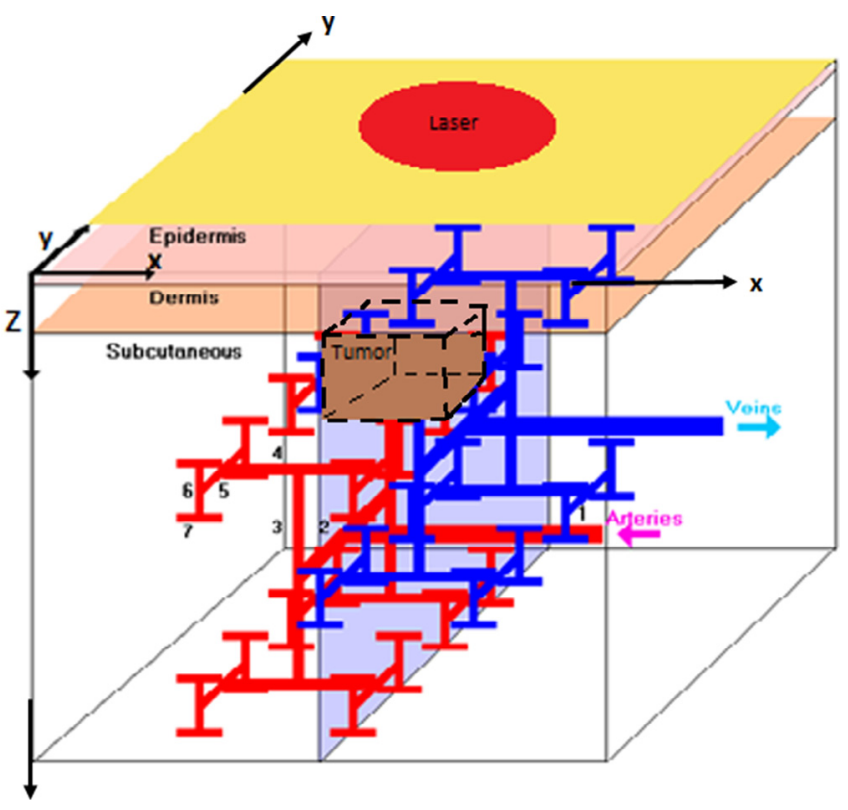

Fig. 1. Three-dimensional triple-layered skin structure with seven levels of countercurrent vasculature and with an embedded tumor.

assumed to double after two consecutive construction steps, which can be expressed in the length-doubling rule as follows:

$L_{b}^{m}=2^{\frac{1}{2}} L_{b}^{m+1}, \quad m=1, \ldots, 6$,

where $L_{b}^{m}$ is the length of the blood vessel in level $m$. The mass flow of blood in the $m$ th level vessel, $M_{m}=v_{m} F_{m}$, satisfies

$M_{m}=2 M_{m+1}, \quad m=1, \ldots, 6$,

where $v_{m}$ is the blood flow velocity and $F_{m}\left(=N L_{b}^{m} \times N W_{b}^{m}\right)$ is the area of the cross-section in the $m$ th level vessel.

For the blood flow in the vascular countercurrent network, we assume that the blood temperature in the cross-section of a vessel is assumed to be uniform. We further assume that a steady-state energy balance in the blood vessel can be reached because the length of the considered blood vessel is relatively short and the blood velocity is relatively high. However, one may use the transient heat transfer equation for a more accurate solution. Hence, the convective energy balance equations, which are used to calculate the artery (levels 1-6) blood temperatures, can be expressed as [12-14,45-47]

$$
\begin{aligned}
& C_{B} M_{1} \frac{\partial T_{b}^{1}}{\partial x}-\alpha P_{1}\left(T_{w}^{1}-T_{b}^{1}\right)=0, \\
& C_{B} M_{2} \frac{\partial T_{b}^{2}}{\partial y}-\alpha P_{2}\left(T_{w}^{2}-T_{b}^{2}\right)=0, \\
& C_{B} M_{3} \frac{\partial T_{b}^{3}}{\partial z}-\alpha P_{3}\left(T_{w}^{3}-T_{b}^{3}\right)=0, \\
& C_{B} M_{4} \frac{\partial T_{b}^{4}}{\partial x}-\alpha P_{4}\left(T_{w}^{4}-T_{b}^{4}\right)=0, \\
& C_{B} M_{5} \frac{\partial T_{b}^{5}}{\partial y}-\alpha P_{5}\left(T_{w}^{5}-T_{b}^{5}\right)=0, \\
& C_{B} M_{6} \frac{\partial T_{b}^{6}}{\partial z}-\alpha P_{6}\left(T_{w}^{6}-T_{b}^{6}\right)=0,
\end{aligned}
$$

where $C_{B}$ is the heat capacity of blood, $\alpha$ is the heat transfer coefficient between blood and tissue, and $P_{m}$ is the vessel perimeter. In addition, $T_{w}^{m}$ and $T_{b}^{m}$ are the wall temperature and the blood temperature in the $m$ th level vessel. For the smallest, terminal arterial vessels (level 7), a blood flow rate $(\dot{P})$ is included in the energy balance equation

$C_{B} M_{7} \frac{\partial T_{w}^{7}}{\partial x}-\alpha P_{7}\left(T_{w}^{7}-T_{b}^{7}\right)-\dot{P} C_{B} F_{7} T_{b}^{7}=0$.

The venous network is assumed to be similar to the arterial network, except that the blood flow direction in each vein is opposite of that in the artery; i.e., countercurrent flow occurs in these two kinds of vessels (see Fig. 1). Also, the diameter ratio, length ratio, and mass flow ratio of the blood between the successive levels of the branched veins take the same form, as shown in Eqs. (1)-(3) for the arteries. Moreover, the convective energy balance Eqs. (4a) $-(4 \mathrm{~g})$ used to calculate the blood temperature in the artery domain are applied to the vein domain at the corresponding levels.

\subsection{Bioheat transfer equation}

For the skin tissue, the modified Pennes' equation that gives the temperature distribution in a 3-D triple-layered skin tissue can be written as follows [8-10,13,14]:

$$
\begin{aligned}
\rho_{l} C_{l}\left(\frac{\partial T_{l}}{\partial t}+\tau_{l} \frac{\partial^{2} T_{l}}{\partial t^{2}}\right) & +\tau_{l} W_{b}^{l} C_{b}^{l} \frac{\partial T_{l}}{\partial t}=k_{l}\left(\frac{\partial^{2} T_{l}}{\partial x^{2}}+\frac{\partial^{2} T_{l}}{\partial y^{2}}+\frac{\partial^{2} T_{l}}{\partial z^{2}}\right) \\
& +W_{b}^{l} C_{b}^{l}\left(T_{\text {out }}-T_{l}\right)+Q_{l}+\tau_{l} \frac{\partial Q_{l}}{\partial t}, \quad l=1,2,3 .
\end{aligned}
$$

Here, $T_{l}$ is the temperature of the lth skin tissue layer; $T_{\text {out }}$ is the blood temperature at the exit or entrance of the seventh level vessel for the artery or vein; $\rho_{l}, C_{l}$, and $k_{l}$ denote the density, specific heat, and thermal conductivity of the lth skin tissue layer, respectively; $C_{b}^{l}$ is the specific heat of blood; $W_{b}^{l}$ is the blood perfusion rate; and $Q_{l}$ is the volumetric heating due to spatial heating. $\tau_{l}$ is the relaxation time due to the thermal lag of the heat flux in the $l$ th skin tissue layer. Note that when $\tau_{l}$ is zero, the above equation reduces to the Pennes' equation. It should be pointed out that Eq. (5) is obtained based on the CV (Cattaneo-Vernotte) model which introduces a phase lag into the heat flux and has taken into account the nonhomogeneous cell structures such as scattering properties.

Since the tumor has golden nanoshells embedded into the tissue, we must consider the effective thermal conductivities and heat capacities for the part of the tumor region that contains the golden nanoshells. Although they can be calculated using some other different formulas, such as $\frac{1}{\left(k_{t}\right)_{\text {eff }}}=\frac{\varepsilon_{t}}{k_{g p}}+\frac{1-\varepsilon_{t}}{k_{t}}[48,49]$, we take a weighted average to obtain them as follows [50]:

$\left(k_{t}\right)_{e f f}=\varepsilon_{t} k_{g p}+\left(1-\varepsilon_{t}\right) k_{t}$,

$(\rho C)_{e f f}=\varepsilon_{t} \rho_{\text {gold }} C_{\text {gold }}+\left(1-\varepsilon_{t}\right) \rho_{t} C_{t}$,

where $\varepsilon_{t}$ and $k_{g p}$ are the porosity of the tumor and the thermal conductivity of the gold nanoshells, respectively. Similarly, $C_{\text {gold }}$ and $\rho_{\text {gold }}$ are the specific heat capacity and density of gold, respectively. The porosity of the tumor, $\varepsilon_{t}$, is defined as the volume fraction of empty space that is not occupied by the tumor tissue. In our study, the gold nanoshells are assumed to occupy the empty space and to be uniformly distributed in the nanoshell-embedded region inside the tumor region. Here, we consider the nanoshell-embedded region to be slightly smaller than the entire tumor region, in order to avoid diffusing the heat quickly to the healthy tissue surrounding the tumor and hence possibly damaging the healthy tissue. In other words, we are using the tumor region without nanoshells as a buffer zone so that the healthy tissue does not rise to the hyperthermia 
levels while the tumor tissue is raised to the hyperthermia levels. However, for the tumor region outside of the nanoshellembedded region, we set $\varepsilon_{t}=0$. Furthermore, we refer the related heat transfer in porous media to these recent articles in [51-53]. Here, $k_{g p}$ is given based on

$k_{\text {gp }}=\frac{k_{\text {gold }}}{1+K_{n}}$,

where $K_{n}$ is the Knudsen number defined as $K_{n}=\lambda_{\text {ep }} / D_{p}$, and $k_{\text {gold }}$ is the thermal conductivity of gold. It should be noted that $\lambda_{e p}$ and $D_{p}$ are the effective mean free path of the electron and the diameter of the gold nanoshells, respectively. Furthermore, the tumor region has a different thermal lag, $\tau_{t}$, than the healthy tissue region $[54,55]$. Thus, the modified Pennes' equation in the tumor region can be written as

$$
\begin{aligned}
& (\rho C)_{e f f}\left(\frac{\partial T_{t}}{\partial t}+\tau_{t} \frac{\partial^{2} T_{t}}{\partial t^{2}}\right)+\tau_{t} W_{b}^{t} C_{b}^{t} \frac{\partial T_{t}}{\partial t} \\
& =\left(k_{t}\right)_{e f f}\left(\frac{\partial^{2} T_{t}}{\partial x^{2}}+\frac{\partial^{2} T_{t}}{\partial y^{2}}+\frac{\partial^{2} T_{t}}{\partial z^{2}}\right)+W_{b}^{t} C_{b}^{t}\left(T_{\text {out }}-T_{t}\right)+Q_{t}+\tau_{t} \frac{\partial Q_{t}}{\partial t},
\end{aligned}
$$

where $Q_{t}$ is the volumetric heating in the tumor region.

\subsection{Heat source}

We assume that the laser power is continuous and spatial with a normal distribution and express the heat source $Q_{l}$ as $[13,56]$ :

$Q_{1}=\alpha_{1} e^{-\alpha_{1} z} \frac{1}{\sqrt{2 \pi \sigma^{2}}} e^{-\left\{\left[x-x_{0}(t)\right]^{2}+\left[y-y_{0}(t)\right]^{2}\right\} / 2 \sigma^{2}} P_{0}\left(1-\operatorname{Reff}_{1}\right)$,

$Q_{2}=\alpha_{2} e^{-\alpha_{1} L_{1}-\alpha_{2} z} \frac{1}{\sqrt{2 \pi \sigma^{2}}} e^{-\left\{\left[x-x_{0}(t)\right]^{2}+\left[y-y_{0}(t)\right]^{2}\right\} / 2 \sigma^{2}} P_{0}\left(1-\operatorname{Reff}_{2}\right)$,

$Q_{3}=\alpha_{3} e^{-\alpha_{1} L_{1}-\alpha_{2} L_{2}-\alpha_{3} z} \frac{1}{\sqrt{2 \pi \sigma^{2}}} e^{\left.-\left\{\left[x-x_{0}(t)\right]^{2}+\left[y-y_{0}(t)\right]^{2}\right\}\right) / 2 \sigma^{2}} P_{0}\left(1-\operatorname{Reff}_{3}\right)$,

where $\alpha_{1}, \alpha_{2}, \alpha_{3}$ are laser absorptivities of the three layers, respectively; $\operatorname{Reff}_{1}, \operatorname{Reff}_{2}$, and $\operatorname{Reff}_{3}$ are laser reflectivities of the three layers of the skin, respectively; $\sigma$ is the standard deviation of the width of a normally distributed laser beam; and $L_{1}, L_{2}$, and $L_{3}$ are depths of the three layers, respectively. Here, $\left[x_{0}(t), y_{0}(t)\right]$ is the location where the laser is focused at time $t . P_{0}$ is the laser intensity, which will be determined later, so that an optimal temperature distribution can be obtained.

However, in the nanoshell-embedded tumor region, the heat source is different. Here, we consider the nanoshells' heat spectrum in conjunction with the heat generation from the laser and give the heat source as

$Q_{t}=\varepsilon_{t} u^{\prime \prime \prime}+\left(1-\varepsilon_{t}\right) Q_{3}$

where $u^{\prime \prime \prime}$ represents the local heat generation spectrum being generated by the gold nanoshells in the tumor region in which the derivation is given in $[23,24]$ and can be seen in Appendix.

It should be pointed out that because the heat source in Eq. (9) is a 2-D Gaussian distribution, the main heating spot area can be calculated by the formula: $2 \pi \int_{0}^{R} e^{-r^{2} / 2 \sigma^{2}} r d r=\sigma^{2}\left(1-e^{-R^{2} / 2 \sigma^{2}}\right)$, where $R$ is the radius of the spot. For instance, if taking the ratio of the main heating spot area over the total heating area to be $95 \%$, one may obtain $R \approx 2 \sigma$.

\subsection{Boundary, initial, and interfacial conditions}

On the skin surface, we assume that heat exchanges with the surrounding and there is a thermal lag of the heat flux on the surface. Thus, combining $-k_{1} \frac{\partial T_{1}}{\partial z}=q_{1}+\tau_{1} \frac{\partial q_{1}}{\partial t}$ with $q_{1}=h\left(T_{1}-T_{a}\right)$, we obtain a boundary condition as

$k_{1} \frac{\partial T_{1}}{\partial z}=h\left(T_{1}-T_{a}\right)+\tau_{1} h \frac{\partial T_{1}}{\partial t}$,

where $h$ is the convective heat transfer coefficient, $q_{1}$ is the heat flux of the first layer in the $z$ direction, and $T_{a}$ is the ambient temperature. For simplicity, other boundary conditions in the tissue are assumed to be $[9,13,14]$

$\frac{\partial T_{l}}{\partial \vec{n}}=0$,

where $\vec{n}$ is the unit outward normal vector on the boundary. At the entrance to the first level vessel, we have

$T_{b}^{1}=T_{\text {in }}$,

where $T_{\text {in }}$ is the blood temperature at the entrance of the artery. At the exit of the artery, the blood temperature is equal to the surrounding tissue temperature

$T_{b}^{7}=T_{\text {out }}$.

The continuity of heat transfer between the lateral blood vessel and the tissue requires $[13,14]$

$\frac{\partial T_{b}^{m}}{\partial \vec{n}}=B_{i}\left(T_{w}^{m}-T_{b}^{m}\right), m=1, \ldots, 7$

The interfacial condition between three skin tissue layers and the tumor is assumed to be perfectly thermal contact and is given by $[13,14]$

$T_{1}=T_{2}, \quad k_{1} \frac{\partial T_{1}}{\partial z}=k_{2} \frac{\partial T_{2}}{\partial z}, \quad z=L_{1}$

$T_{2}=T_{3}, \quad k_{2} \frac{\partial T_{2}}{\partial z}=k_{3} \frac{\partial T_{3}}{\partial z}, \quad z=L_{1}+L_{2}$

$T_{3}^{\text {in }}=T_{3}^{\text {out }}, \quad k_{3} \frac{\partial T_{3}}{\partial z}=k_{t} \frac{\partial T_{3}^{\text {in }}}{\partial z}$,

$z=L_{t}, \quad \frac{L X}{3} \leqslant x \leqslant \frac{2 L X}{3}, \quad \frac{L Y}{3} \leqslant y \leqslant \frac{2 L Y}{3} ;$

$T_{3}^{\text {in }}=T_{3}^{\text {out }}, \quad k_{t} \frac{\partial T_{3}^{\text {in }}}{\partial z}=k_{3} \frac{\partial T_{3}^{\text {out }}}{\partial z}$,

$z=L_{t}+L_{T}, \quad \frac{L X}{3} \leqslant x \leqslant \frac{2 L X}{3}, \quad \frac{L Y}{3} \leqslant y \leqslant \frac{2 L Y}{3} ;$

$T_{3}^{\text {in }}=T_{3}^{\text {out }}, \quad k_{t} \frac{\partial T_{3}^{\text {in }}}{\partial y}=k_{3} \frac{\partial T_{3}^{\text {out }}}{\partial y}$,

$y=\frac{L Y}{3}, \quad \frac{2 L Y}{3}, \quad L_{t} \leqslant z \leqslant L_{t}+L_{T}, \quad \frac{L X}{3} \leqslant x \leqslant \frac{2 L X}{3} ;$

$T_{3}^{\text {in }}=T_{3}^{\text {out }}, \quad k_{t} \frac{\partial T_{3}^{\text {in }}}{\partial x}=k_{3} \frac{\partial T_{3}^{\text {out }}}{\partial x}$,

$x=\frac{L X}{3}, \quad \frac{2 L X}{3}, \quad L_{t} \leqslant z \leqslant L_{t}+L_{T}, \quad \frac{L Y}{3} \leqslant y \leqslant \frac{2 L Y}{3}$,

where $L_{T}$ and $L_{t}$ are the length of the tumor and the location of the top of the tumor region in the $z$-direction, respectively. Due to part of the tumor's interior being saturated with golden nanoshells, we employ the following interfacial condition for the nanoshellembedded region within the tumor as 
$T_{3}^{i n}=T_{3}^{e f f}, \quad k_{t} \frac{\partial T_{3}^{i n}}{\partial \vec{n}}=\left(k_{t}\right)_{e f f} \frac{\partial T_{3}^{e f f}}{\partial \vec{n}}$.

Because the blood flow in the vein is oriented against the arterial flow, the entrance of the blood to the vein is located at the 7th level, and the blood temperature is equal to the surrounding tissue temperature. The initial conditions are assumed to be

$T_{l}=T_{t}=T_{0}, \quad \frac{\partial T_{l}}{\partial t}=\frac{\partial T_{t}}{\partial t}=0, t=0, l=1,2,3$,

where $T_{t}$ is the temperature in the tumor region, $T_{0}$ is the initial temperature in the tissue, and $T_{1}, T_{2}$, and $T_{3}$ are the tissue temperatures in skin layer one, two and three, respectively.

\section{Numerical method}

\subsection{Finite difference method}

The numerical method includes a stable finite difference scheme for solving the modified Pennes' equation, the fourthorder Runge-Kutta method for blood flow equations, the least squares method for optimizing the laser power, and the computational procedure.

We denote $\left(u_{l}\right)_{i j k}^{n}$ and $u_{b}$ the numerical approximations of $T_{l}(i \Delta x, j \Delta y, k \Delta z, n \Delta t)$ and $T_{b}$, respectively, where $\Delta x, \Delta y, \Delta z$, and $\Delta t$ are the spatial and temporal mesh sizes, and $i, j, k$ are integers, $0 \leqslant i \leqslant N_{x}, 0 \leqslant j \leqslant N_{y}, 0 \leqslant k \leqslant N_{l}^{z}$; so that $N_{x} \Delta x=L X, N_{y} \Delta y=L Y$, and $N_{l}^{z} \Delta z=L_{l}^{z}, l=1,2,3$. In this mesh, we assume that $\left(u_{3}\right)_{i j k}^{n}=\left(u_{b}^{m}\right)_{i j k}$ when the grid point $(i, j, k)$ is in the $m$ th level blood vessel. If $T_{w}^{m}$ is known, then Eqs. (4a)-(4g) for blood temperature become first-order ordinary differential equations, which can be solved by using the fourth-order Runge-Kutta method [57]. Once the blood temperature $u_{b}$ is determined, Eqs. (5)-(18) can be solved by using an unconditionally stable finite difference scheme that was used in $[14,58]$. For convenience, we list those equations as follows:

$$
\frac{\left(s_{l}\right)_{i j k}^{n+1}+\left(s_{l}\right)_{i j k}^{n}}{2}=\left(1+\tau_{l} \frac{W_{b}^{l} C_{b}^{l}}{\rho_{l} C_{l}}\right) \frac{\left(u_{l}\right)_{i j k}^{n+1}+\left(u_{l}\right)_{i j k}^{n}}{2}+\frac{\left(u_{l}\right)_{i j k}^{n+1}-\left(u_{l}\right)_{i j k}^{n}}{\Delta t},
$$

$$
\begin{gathered}
\rho_{l} C_{l} \frac{\left(s_{l}\right)_{i j k}^{n+1}-\left(s_{l}\right)_{i j k}^{n}}{\Delta t}+W_{b}^{l} C_{b}^{l}\left[\frac{\left(u_{l}\right)_{i j k}^{n+1}+\left(u_{l}\right)_{i j k}^{n}}{2}-(u)_{\text {out }}\right] \\
=k_{l}\left(\delta_{x}^{2}+\delta_{y}^{2}+\delta_{z}^{2}\right) \frac{\left(u_{l}\right)_{i j k}^{n+1}+\left(u_{l}\right)_{i j k}^{n}}{2}+\left(Q_{l}\right)_{i j k}^{n+1 / 2}+\tau_{l}\left(\frac{\partial Q_{l}}{\partial t}\right)_{i j k}^{n+1 / 2} \\
\quad l=1,2,3, t
\end{gathered}
$$

where $\left(s_{l}\right)_{i j k}^{n}$ is the numerical approximation of $S_{l}(i \Delta x, j \Delta y, k \Delta z, n \Delta t)$ defined as $S_{l}=\left(1+\tau_{l} \frac{w_{b}^{l} c_{b}^{l}}{\rho_{l} c_{l}}\right) T_{l}+\tau_{l} \frac{\partial T_{l}}{\partial t}, \delta_{x}^{2} u_{i j k}=\frac{u_{i-1 j k}-2 u_{i j k}+u_{i+1 j k}}{\Delta x^{2}}$ and so on, for the $y$ and $z$ directions. Similar scheme can be obtained for Eq. (8). It should be pointed out that the unconditional stability of the above scheme (Eqs. (19) and (20)) can be proved using a similar argument to that in [59].

The discrete interfacial equations for Eq. (16) is assumed to be, for any time level,

$$
k_{1} \frac{\left(u_{1}\right)_{i j N_{1}^{z}}^{n}-\left(u_{1}\right)_{i j N_{1}^{z}-1}^{n}}{\Delta z}=k_{2} \frac{\left(u_{2}\right)_{i j 1}^{n}-\left(u_{2}\right)_{i j 0}^{n}}{\Delta z}, \quad\left(u_{1}\right)_{i j N_{1}^{z}}^{n}=\left(u_{2}\right)_{i j 0}^{n} \text {; }
$$

$$
k_{2} \frac{\left(u_{2}\right)_{i j N_{2}^{z}}^{n}-\left(u_{2}\right)_{i j N_{2}^{z}-1}^{n}}{\Delta z}=k_{3} \frac{\left(u_{3}\right)_{i j 1}^{n}-\left(u_{3}\right)_{i j 0}^{n}}{\Delta z}, \quad\left(u_{2}\right)_{i j N_{2}^{z}}^{n}=\left(u_{3}\right)_{i j 0}^{n} .
$$

Similar discrete interfacial equations can be obtained for the rest of Eqs. (16) and (17). The interfacial condition, Eq. (15), between the tissue and the lateral blood vessel is discretized as follows

$\left(u_{3}\right)_{i j k}^{n+1}=\frac{\left(u_{3}\right)_{i+1 j k}^{n+1}+B_{i} \Delta x\left(u_{3}\right)_{i-1 j k}^{n+1}}{\left(1+B_{i} \Delta x\right)}$,

and similar discrete equations for the $y$ and $z$ directions, where the grid point $(i, j, k)$ is on the lateral walls of the blood vessel in the $x, y, z$ directions, respectively. When the grid point $(i, j, k)$ is in the tissue, the initial and other boundary conditions are discretized as follows:

$\left(u_{l}\right)_{i j k}^{0}=T_{0}, \quad\left(s_{l}\right)_{i j k}^{0}=0 ;$

$\left(u_{l}\right)_{0 j k}^{n}=\left(u_{l}\right)_{1 j k}^{n}, \quad\left(u_{l}\right)_{N_{x} j k}^{n}=\left(u_{l}\right)_{N_{x}-1 j k}^{n}$

$\left(u_{l}\right)_{i 0 k}^{n}=\left(u_{l}\right)_{i 1 k}^{n}, \quad\left(u_{l}\right)_{i N_{y} k}^{n}=\left(u_{l}\right)_{i N_{y}-1 k}^{n}$;

$k_{1} \frac{\left(u_{1}\right)_{i j 1}^{n}-\left(u_{1}\right)_{i j 0}^{n}}{\Delta z}=h\left[\left(u_{1}\right)_{i j 0}^{n}-T_{a}\right]+\tau_{1} h \frac{\left(u_{1}\right)_{i j 0}^{n+1}-\left(u_{1}\right)_{i j 0}^{n}}{\Delta t} ;$

$\left(u_{3}\right)_{i j 0}^{n}=\left(u_{3}\right)_{i j 1}^{n}, \quad\left(u_{3}\right)_{i j N_{3}^{z}}^{n}=\left(u_{3}\right)_{i j N_{3}^{z}-1}^{n}$,

for any time level $n$.

\subsection{Least squares method}

To determine the laser intensity $P_{0}$ so that an optimal temperature distribution can be obtained, we pre-specify the temperature elevations to be obtained at the center of the tumor and some locations in the perimeter on the skin surface. The reason that these locations are chosen is because the highest temperature is assumed to be around the center of the tumor tissue, and it is necessary to have the temperature in the perimeter below a certain threshold so as not to cause damage to the normal tissue. In addition, the temperature can be easily measured at these locations. By guessing an initial laser intensity $P_{0}$ and pre-specifying a laser exposure pattern, one can solve the above equations to obtain a temperature field in the entire 3-D skin structure. Once the temperatures, $u_{\text {cal }}^{i}$, are calculated at the given locations $(i=0,1, \ldots, M)$, a least squares approach can be employed to minimize the difference between the pre-specified temperature $\mathbf{u}_{\text {pre }}$ and the calculated temperature $\mathbf{u}_{\text {cal }}$ as follows:

$S\left(P_{0}\right)=\sum_{i=0}^{M}\left(u_{\text {pre }}^{i}-u_{\text {cal }}^{i}\right)^{2}, \quad i=0,1, \ldots, M$.

Minimizing $S\left(P_{0}\right)$, one obtains

$\frac{d}{d P_{0}} S\left(P_{0}\right)=-2 \sum_{i=0}^{M}\left[\frac{d\left(u_{c a l}^{i}\right)}{d P_{0}}\right]\left(u_{\text {pre }}^{i}-u_{c a l}^{i}\right)=0, \quad i=0,1, \ldots, M$.

Thus, a new $P_{0}$ can be calculated iteratively as follows $[13,60]$ :

$P_{0}^{(J+1)}=P_{0}^{(J)}+\left(\mathbf{X}^{t} \mathbf{X}+\alpha^{*} \mathbf{I}\right)^{-1} \mathbf{X}^{t}\left(\mathbf{u}_{\text {pre }}-\mathbf{u}_{\text {cal }}\right)$,

where $\alpha^{*}$ is a relaxation parameter, $\mathbf{I}$ is an identity matrix, and $\mathbf{X}$ is the sensitivity coefficient matrix, which is an $(M+1) \times 1$ vector

$\mathbf{X}=\left[\frac{\partial\left(u_{c a l}^{0}\right)}{\partial P_{0}}, \frac{\partial\left(u_{c a l}^{1}\right)}{\partial P_{0}}, \ldots, \frac{\partial\left(u_{c a l}^{M}\right)}{\partial P_{0}}\right]^{t}$

and

$\mathbf{u}_{\text {pre }}=\left[u_{\text {pre }}^{0}, u_{\text {pre }}^{1}, \ldots, u_{\text {pre }}^{M}\right]^{t}, \quad \mathbf{u}_{\text {cal }}=\left[u_{\text {cal }}^{0}, u_{c a l}^{1}, \ldots, u_{c a l}^{M}\right]^{t}$. 


\subsection{Computational procedure}

To reduce the computational time, we solve for $\left(s_{l}\right)_{i j k}^{n+1}$ from Eq. (19) and then substitute it into Eq. (20). This gives

$$
\begin{aligned}
\frac{\rho_{l} C_{l}}{\Delta t} & {\left[\left(1+\tau_{l} \frac{W_{b}^{l} C_{b}^{l}}{\rho_{l} C_{l}}+\frac{2 \tau_{l}}{\Delta t}\right)\left(u_{l}\right)_{i j k}^{n+1}\right.} \\
& \left.+\left(1+\tau_{l} \frac{W_{b}^{l} C_{b}^{l}}{\rho_{l} C_{l}}-\frac{2 \tau_{l}}{\Delta t}\right)\left(u_{l}\right)_{i j k}^{n}-2\left(s_{l}\right)_{i j k}^{n}\right] \\
& +W_{b}^{l} C_{b}^{l}\left[\frac{\left(u_{l}\right)_{i j k}^{n+1}-\left(u_{l}\right)_{i j k}^{n}}{2}-\left(u_{b}\right)_{\text {out }}\right] \\
= & k_{l}\left(\delta_{x}^{2}+\delta_{y}^{2}+\delta_{z}^{2}\right) \frac{\left(u_{l}\right)_{i j k}^{n+1}-\left(u_{l}\right)_{i j k}^{n}}{2}+\left(Q_{l}\right)_{i j k}^{n+1 / 2}+\tau_{l}\left(\frac{\partial Q}{\partial t}\right)_{i j k}^{n+1 / 2}, \\
& l=1,2,3, t .
\end{aligned}
$$

We further employ a preconditioned Richardson iteration for $\left(u_{l}\right)_{i j k}^{n+1}$ as follows:

$$
\begin{aligned}
L_{p r e}^{1}\left[\left(u_{l}\right)_{i j k}^{n+1}\right]^{(I+1)}= & L_{p r e}^{1}\left[\left(u_{l}\right)_{i j k}^{n+1}\right]^{(I)} \\
& -\omega\left\{\frac { \rho _ { l } C _ { l } } { \Delta t } \left[\left(1+\tau_{l} \frac{W_{b}^{l} C_{b}^{l}}{\rho_{l} C_{l}}+\frac{2 \tau_{l}}{\Delta t}\right)\left[\left(u_{l}\right)_{i j k}^{n+1}\right]^{(I)}\right.\right. \\
& \left.+\left(1+\tau_{l} \frac{W_{b}^{l} C_{b}^{l}}{\rho_{l} C_{l}}+\frac{2 \tau_{l}}{\Delta t}\right)\left(u_{l}\right)_{i j k}^{n}-2\left(s_{l}\right)_{i j k}^{n}\right] \\
& +W_{b}^{l} C_{b}^{l}\left[\frac{\left[\left(u_{l}\right)_{i j k}^{n+1}\right]^{(I)}+\left(u_{l}\right)_{i j k}^{n}}{2}-\left(u_{b}\right)_{o u t}\right] \\
& -k_{l}\left(\delta_{x}^{2}+\delta_{y}^{2}+\delta_{z}^{2}\right) \frac{\left(\left(u_{l}\right)_{i j k}^{n+1}\right]^{(I)}+\left(u_{l}\right)_{i j k}^{n}}{2} \\
& \left.-\left(Q_{l}\right)_{i j k}^{n+1 / 2}-\tau_{l}\left(\frac{\partial Q_{l}}{\partial t}\right)_{i j k}^{n+1 / 2}\right\}, \quad I=0,1, \ldots
\end{aligned}
$$

where $\omega$ is the relaxation factor, $l=1,2,3, t$, and the preconditioner is chosen to be

$L_{\text {pre }}^{1}=1+\tau_{l} \frac{W_{b}^{l} C_{b}^{l}}{\rho_{l} C_{l}}+\frac{2 \tau_{l}}{\Delta t}+\frac{W_{b}^{l} C_{b}^{l} \Delta t}{2 \rho_{l} C_{l}}\left[\frac{1}{\Delta x^{2}}+\frac{1}{\Delta y^{2}}\right]-\frac{k_{l} \Delta t}{2 \rho_{l} C_{l}} \delta_{z}^{2}$.

It should be pointed out that the convergence for this iteration can be proved using a similar argument to that in [59]. Thus, the linear system, Eq. (29), can be transferred into a tridiagonal linear system, Eqs. (30) and (31). If we denote $\left(u_{3}\right)_{i j k}^{n}=\left(u_{b}^{m}\right)_{i j k}$ when the grid point $(i, j, k)$ is in the $m$ th level blood vessel, then the Thomas algorithm [61] can be used line by line along the $z$-direction. Thus, our computational procedure for predicting the skin's temperature distribution in a 3-D skin structure induced by laser-heating can be described as follows:

Step 1. Pre-specify the temperature levels $u_{\text {pre }}^{i}$ at given $(M+1)$ grid points $i=0,1, \ldots, M$; on the skin surface and the tumor's center, and pre-specify the laser exposure pattern for obtaining these pre-specified temperatures.

Step 2. Guess an initial laser intensity $P_{0}$ and its small increment $P_{0}+\Delta P_{0}$.

Step 3. Guess the wall temperature of the blood vessel $u_{w}^{m}$ and obtain the blood temperature $u_{b}^{m}$ by solving Eqs. (4a)$(4 \mathrm{~g})$ using the fourth-order Runge-Kutta method. It should be pointed out that at each program loop, we first calculate the temperature of each level of blood vessel, where the coordinates of blood vessels are independent of the coordinates of consideration of skin domain.

Step 4. Update the wall temperature of the blood vessel, $u_{w}^{m}$, by Eq. (22).
Step 5. Obtain the temperature distribution $\mathbf{u}_{\text {cal }}$ in the entire 3-D skin structure by solving Eqs. (30) and (31) coupled with the interfacial equations, the initial and boundary conditions, Eqs. (21) $-(24)$.

Step 6. Repeat steps 3-5 until a convergent solution, $\mathbf{u}_{\text {cal }}$, at time level $n+1$ is obtained.

Step 7. Determine a new $P_{0}$ based on Eqs. (27) and (28).

Step 8. Repeat the computation until the following criterion for convergence is satisfied:

$$
\frac{\left|S\left(\left(P_{0}\right)^{(J+1)}\right)-S\left(\left(P_{0}\right)^{(J)}\right)\right|}{S\left(\left(P_{0}\right)^{(J+1)}\right)}<\varepsilon_{\text {laser }}
$$

Step 9. With the optimized $P_{0}$, repeat steps 3-6 for the given time period.

\section{Numerical example}

To illustrate the present method, we chose a 3-D skin structure with the dimensions $1.62 \mathrm{~cm} \times 1.62 \mathrm{~cm} \times 2.6 \mathrm{~cm}$ and with embedded seven-level dendritic countercurrent vascular network, as shown in Fig. 1. The values of the biological parameters used are listed in Table 1. We assumed heat convection occurring on the skin surface $\left(h=0.001 \mathrm{~W} / \mathrm{cm}^{2}\right.$ ) where the surface is exposed to an ambient temperature of $25^{\circ} \mathrm{C}$. The thermal relaxation time was taken to be $\tau_{1}=\tau_{2}=\tau_{3}=20 \mathrm{~s}$ for the healthy skin tissue [8] and $\tau_{t}=6.825 \mathrm{~s}$ for the tumor region [55]. Other parameters used in these computations are listed in Tables 2 and 3. The tumor region is in the volume of $0.54 \mathrm{~cm} \leqslant x \leqslant 1.08 \mathrm{~cm}, 0.54 \mathrm{~cm} \leqslant y \leqslant$ $1.08 \mathrm{~cm}, 0.240 \mathrm{~cm} \leqslant z \leqslant 0.490 \mathrm{~cm}$ and the nanoshell-embedded region within the tumor exists in the volume of $0.65 \mathrm{~cm} \leqslant x \leqslant 0.97 \mathrm{~cm}, \quad 0.65 \mathrm{~cm} \leqslant y \leqslant 0.97 \mathrm{~cm}, \quad 0.315 \mathrm{~cm} \leqslant z \leqslant$ $0.415 \mathrm{~cm}$. It should be pointed out that values of the thermal parameters for the tumor region were chosen based on those given in [63]. Depending on the detailed situation, one may choose different values given in $[48,49]$.

The pattern of the laser irradiation was designed as follows. The laser with beam width of $0.1 \mathrm{~cm}$ was focused on the center of the skin surface, which gives a heating spot around $0.4 \mathrm{~cm}$ in diameter with $95 \%$ heating. The pre-specified temperatures, $\mathbf{u}_{\text {pre }}$, for the center of the tumor and four perimeters of the skin's surface are defined as $\mathbf{u}_{\text {pre }}=[54.0,34.0,34.0,34.0,34.0]^{t}$. When the tumor's center temperature rose to $54^{\circ} \mathrm{C}$, the laser was turned off; the laser was then turned on when the temperature at the center of the tumor decreased by $4{ }^{\circ} \mathrm{C}$. Our goal was to raise the tumor's central temperature from $34^{\circ} \mathrm{C}$ to $54^{\circ} \mathrm{C}$ within $10 \mathrm{~s}$ while maintaining the minimum temperature of the tumor region to be $42^{\circ} \mathrm{C}$. Once the optimized laser intensity was obtained, we then took the optimized laser intensity and obtained the temperature distribution for $600 \mathrm{~s}$. Here, we assumed that our laser is exciting the nanoshells at 633-nm to exhibit peak absorption and minimal scattering [23-25] and that the number of nanoshells occupying a defined voxel of $0.01 \mathrm{~cm} \times 0.01 \mathrm{~cm} \times 0.001 \mathrm{~cm}$ is $7.0 \times 10^{9}$ particles $/ \mathrm{cm}^{3}$. Parameters used in obtaining local heat generation spectrum being generated by the gold nanoshells are listed in Table 3 .

It should be pointed out that the wavelength $(633 \mathrm{~nm})$ was selected here because a laser at this wavelength would have a high transmissivity [25]. This allows for low absorption of the laser when it comes into contact with whole blood and water in the tissue, implying that the laser would have little effect on healthy, blood-filled tissue such as the skin. Second, it is based on the geometry of the nanoshells used. The optimal nanoshell geometry is constructed based on Mie theory such that the configuration exhibits peak absorption with minimal scattering. As a result at the wavelength $(633 \mathrm{~nm})$ being used, the nanoshell geometry with a core radius of $16 \mathrm{~nm}$, a shell thickness of $6 \mathrm{~nm}$, and a tolerance of 
Table 1

Parameters for a 3-D skin structure $[8,13,14,63]$.

\begin{tabular}{cccc}
\hline Parameters & Values & Parameters & Values \\
\hline$C_{1}\left(\mathrm{~J} / \mathrm{g}^{\circ} \mathrm{C}\right)$ & 3.6 & $\rho_{t}\left(\mathrm{~g} / \mathrm{cm}^{3}\right)$ & 1 \\
$C_{2}\left(\mathrm{~J} / \mathrm{g}^{\circ} \mathrm{C}\right)$ & 3.4 & $\rho_{\text {gold }}\left(\mathrm{g} / \mathrm{cm}^{3}\right)$ & 19.3 \\
$C_{3}\left(\mathrm{~J} / \mathrm{g}^{\circ} \mathrm{C}\right)$ & 3.06 & $(\rho C)_{\text {eff }}\left(\mathrm{J} / \mathrm{cm}^{3}{ }^{\circ} \mathrm{C}\right)$ & $3.5027,3.75$ \\
$C_{t}\left(\mathrm{~J} / \mathrm{g}^{\circ} \mathrm{C}\right)$ & 3.75 & $R e f f_{1}$ & 0.1 \\
$C_{\text {gold }}\left(\mathrm{J} / \mathrm{g}^{\circ} \mathrm{C}\right)$ & 0.129 & $\operatorname{Reff} 2$ & 0.1 \\
$C_{b}^{1}\left(\mathrm{~J} / \mathrm{g}^{\circ} \mathrm{C}\right)$ & 0 & $R e f f_{3}$ & 0.1 \\
$C_{b}^{2}\left(\mathrm{~J} / \mathrm{g}^{\circ} \mathrm{C}\right)$ & 4.2 & $\alpha_{1}(1 / \mathrm{cm})$ & 1.8 \\
$C_{b}^{3}\left(\mathrm{~J} / \mathrm{g}^{\circ} \mathrm{C}\right)$ & 4.2 & $\alpha_{2}\left(1 / \mathrm{cm}^{\circ}\right)$ & 1.8 \\
$C_{b}^{t}\left(\mathrm{~J} / \mathrm{g}^{\circ} \mathrm{C}\right)$ & 4.2 & $\alpha_{3}\left(1 / \mathrm{cm}^{\circ}\right)$ & 1.8 \\
$k_{1}\left(\mathrm{~W} / \mathrm{cm}^{\circ} \mathrm{C}\right)$ & 0.0026 & $\alpha_{b}^{1}\left(\mathrm{~g} / \mathrm{cm}^{2} \mathrm{~s}\right)$ & 1.8 \\
$k_{2}\left(\mathrm{~W} / \mathrm{cm}^{\circ} \mathrm{C}\right)$ & 0.0052 & $W_{b}^{2}\left(\mathrm{~g} / \mathrm{cm}^{2} \mathrm{~s}\right)$ & 0 \\
$k_{3}\left(\mathrm{~W} / \mathrm{cm}^{\circ} \mathrm{C}\right)$ & 0.0021 & $W_{b}^{3}\left(\mathrm{~g} / \mathrm{cm}^{2} \mathrm{~s}\right)$ & 0.005 \\
$k_{t}\left(\mathrm{~W} / \mathrm{cm}^{\circ} \mathrm{C}\right)$ & 0.00642 & $W_{b}^{t}\left(\mathrm{~g} / \mathrm{cm}^{2} \mathrm{~s}\right)$ & 0.005 \\
$k_{\text {gold }}\left(\mathrm{W} / \mathrm{cm}^{\circ} \mathrm{C}\right)$ & 3.17 & $v_{1}\left(\mathrm{~cm}^{\circ}\right)$ & 8.0 \\
$k_{g p}\left(\mathrm{~W} / \mathrm{cm}^{\circ} \mathrm{C}\right)$ & 1.7405 & $\alpha\left(\mathrm{W} / \mathrm{cm}^{2}{ }^{\circ} \mathrm{C}\right)$ & 0.2 \\
$k_{\text {eff }}\left(\mathrm{W} / \mathrm{cm}^{\circ} \mathrm{C}\right)$ & $1.2745,0.00642$ & $\dot{P}(1 / \mathrm{s})$ & $0.5 \times 10^{-3}$ \\
$\rho_{1}\left(\mathrm{~g} / \mathrm{cm}^{3}\right)$ & 1.2 & $h\left(\mathrm{~W} / \mathrm{cm}^{2}\right)$ & 0.001 \\
$\rho_{2}\left(\mathrm{~g} / \mathrm{cm}^{3}\right)$ & 1.2 & $C_{B}\left(\mathrm{~J} / \mathrm{cm}^{3}{ }^{\circ} \mathrm{C}\right)$ & 4.134 \\
$\rho_{3}\left(\mathrm{~g} / \mathrm{cm}^{3}\right)$ & 1 & & \\
& & &
\end{tabular}

Table 2

Parameters used in computations.

\begin{tabular}{cccc}
\hline Parameters & Values & Parameters & Values \\
\hline$B_{i}=\alpha / k_{3}$ & 95.23 & $N L_{b}^{3}, N W_{b}^{3}(\mathrm{~cm})$ & 0.12 \\
$L_{1}(\mathrm{~cm})$ & 0.008 & $N L_{b}^{4}, N W_{b}^{4}(\mathrm{~cm})$ & 0.1 \\
$L_{2}(\mathrm{~cm})$ & 0.2 & $N L_{b}^{5}, N W_{b}^{5}(\mathrm{~cm})$ & 0.08 \\
$L_{T}(\mathrm{~cm})$ & 0.25 & $N L_{b}^{6}, N W_{b}^{6}(\mathrm{~cm})$ & 0.06 \\
$L_{t}(\mathrm{~cm})$ & 0.24 & $N L_{b}^{7}, N W_{b}^{7}(\mathrm{~cm})$ & 0.04 \\
$L_{3}(\mathrm{~cm})$ & 1.792 & $T_{0}\left({ }^{\circ} \mathrm{C}\right)$ & 34 \\
$L_{b}^{1}(\mathrm{~cm})$ & 1.0 & $T_{\text {in }}\left({ }^{\circ} \mathrm{C}\right)$ & 37 \\
$L_{b}^{2}(\mathrm{~cm})$ & 0.72 & $\Delta x(\mathrm{~cm})$ & $0.01,0.005$ \\
$L_{b}^{3}(\mathrm{~cm})$ & 0.5 & $\Delta y(\mathrm{~cm})$ & $0.01,0.005$ \\
$L_{b}^{4}(\mathrm{~cm})$ & 0.36 & $\Delta z(\mathrm{~cm})$ & 0.001 \\
$L_{b}^{5}(\mathrm{~cm})$ & 0.26 & $\sigma(\mathrm{cm})$ & 0.1 \\
$L_{b}^{6}(\mathrm{~cm})$ & 0.18 & $\tau_{1}, \tau_{2}, \tau_{3}(\mathrm{~s})$ & $20[8]$ \\
$L_{b}^{7}(\mathrm{~cm})$ & 0.14 & $\tau_{t}(\mathrm{~s})$ & $6.825[55]$ \\
$L X, L Y(\mathrm{~cm})$ & 1.62 & $\varepsilon_{t}$ & $0.4,0$ \\
$L Z(\mathrm{~cm})$ & 2.6 & $T_{a}\left({ }^{\circ} \mathrm{C}\right)$ & \\
$N L_{b}^{1}, N W_{b}^{1}(\mathrm{~cm})$ & 0.2 & & \\
$N L_{b}^{2}, N W_{b}^{2}(\mathrm{~cm})$ & 0.16 & & \\
$\varepsilon_{\text {laser }}$ & 0.02 & & \\
\hline & & & \\
\hline
\end{tabular}

Table 3

Parameters used in obtaining local heat generation spectrum being generated by the gold nanoshells $[23,24,50]$.

\begin{tabular}{cc}
\hline Parameters & Values \\
\hline$N_{T}\left(\right.$ Particles $\left./ \mathrm{cm}^{3}\right)$ & $7.0 \times 10^{9}$ \\
$Q_{k \lambda}($ efficiency $)$ & 0.059492 \\
$Q_{\sigma \lambda}($ efficiency $)$ & 0.0092968 \\
$R_{i}(\mathrm{~cm})$ & $1.6 \times 10^{-6}$ \\
$R_{o}(\mathrm{~cm})$ & $2.2 \times 10^{-6}$ \\
$D_{p}(\mathrm{~cm})$ & $4.4 \times 10^{-6}$ \\
$\lambda_{\text {ep }}(\mathrm{cm})$ & $3.614 \times 10^{-6}$ \\
$\sigma_{m d-\lambda}(1 / \mathrm{cm})$ & 66.9 \\
$k_{m d-\lambda}(1 / \mathrm{cm})$ & 0.1 \\
$\omega_{\lambda}$ & 0.9984 \\
$\epsilon_{\lambda}$ & 1.0 \\
$\beta_{\text {tot }-\lambda}$ & 67.0073 \\
$\omega_{s-\lambda}(1 / \mathrm{cm})$ & $9.8952 \times 10^{-4}$ \\
$k_{s-\lambda}(1 / \mathrm{cm})$ & $6.3 \times 10^{-3}$ \\
$\alpha_{\text {gold }}(1 / \mathrm{cm})$ & 5.76969 \\
\hline
\end{tabular}

$1 \mathrm{~nm}$ has a peak absorption with minimal scattering, making it a prime suspect to allow maximum absorption of the laser for the nanoshells while having minimal scattering in the healthy, or anomalous, native tissue. Furthermore, the density of the nanoshells was chosen based on the sources given in $[23,24]$. The assumption being if we have more nanoshells in the nanoshellmediated region of the tumor, then it would offset the need for a stronger laser because a higher-powered laser may increase the risk for damaging healthy tissue that is in the path of the laser. We would like to point out here that a latest article [62] presented a numerical investigation of thermal response of laser-irradiated biological tissue phantoms embedded with gold nanoshells and discussed the influence of the concentration of embedded nanoshells on absorption, scattering and total extinction coefficients. This could be an effective way to determine the optimal concentration of nanoshells.

We performed two studies using this model in the mesh of $162 \times 162 \times 2600$ : one where nanoshells exist in part of the tumor region $\left(\varepsilon_{t}=0.4\right)$ and the other where no nanoshells exist in the tumor region $\left(\varepsilon_{t}=0\right)$. For the study where nanoshells are

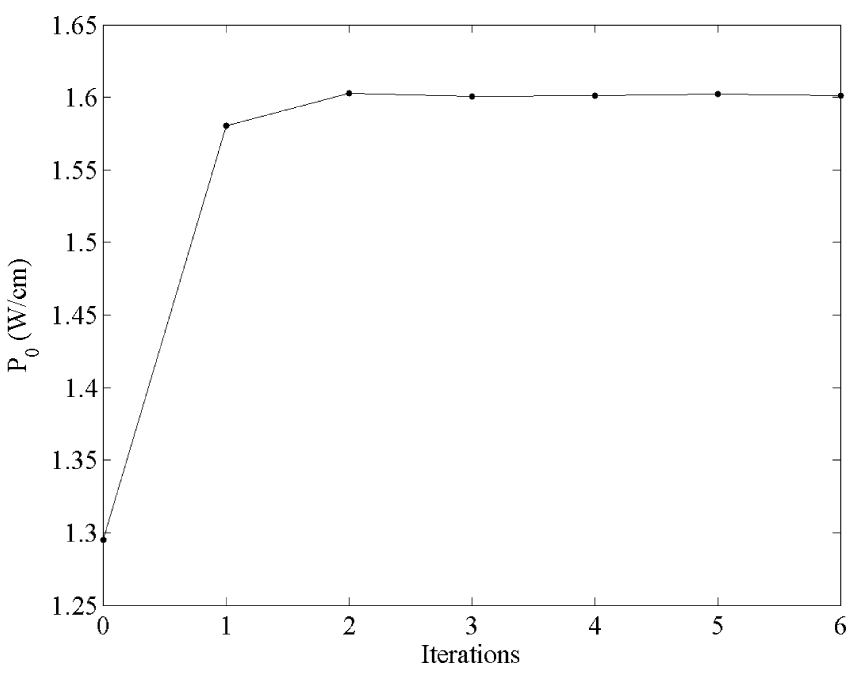

(a)

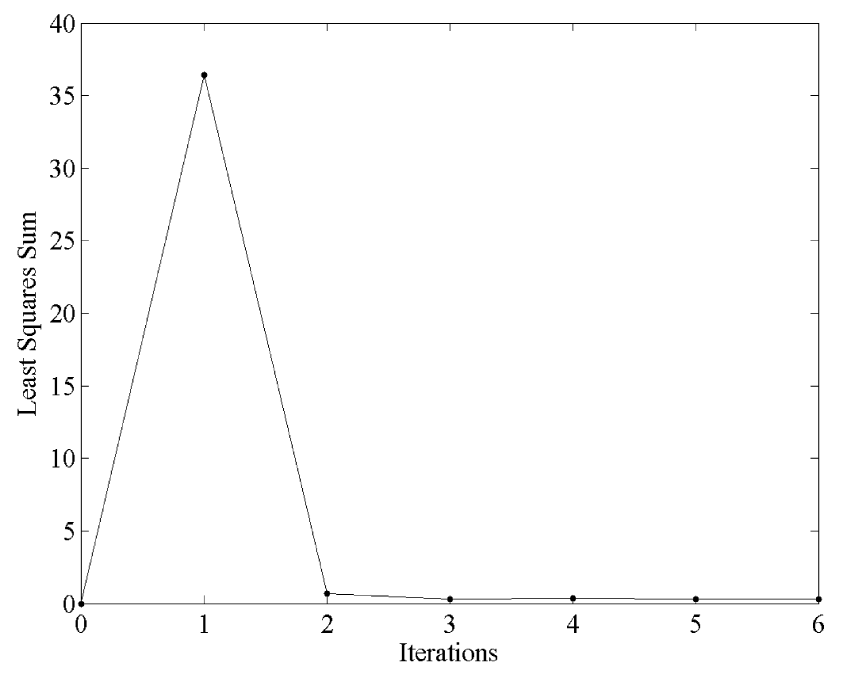

(b)

Fig. 2. Number of iterations versus (a) laser intensity $\left(P_{0}\right)$, and (b) least squares sum, $S\left(P_{0}\right)$. 


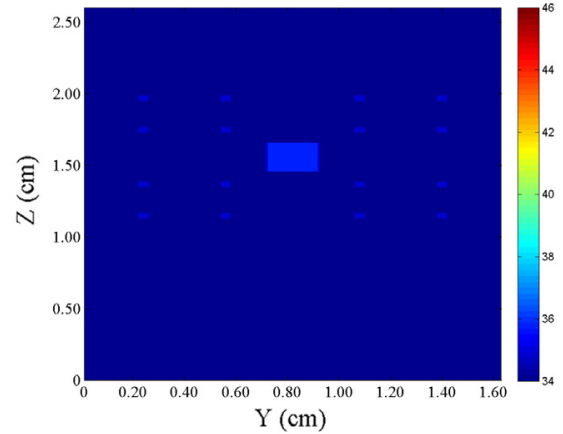

(a)

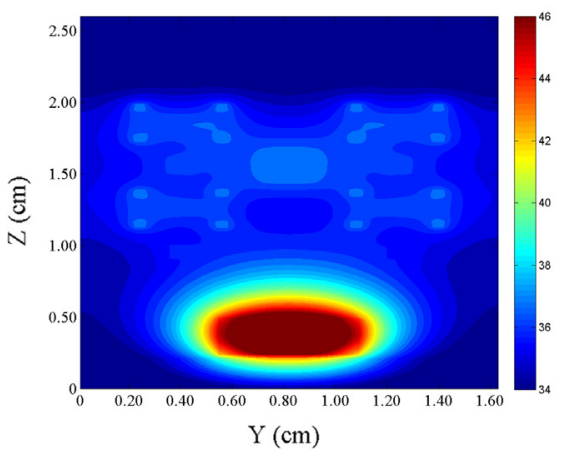

(d)

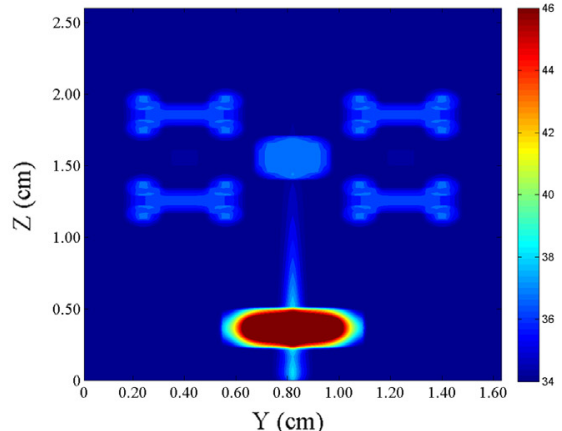

(b)

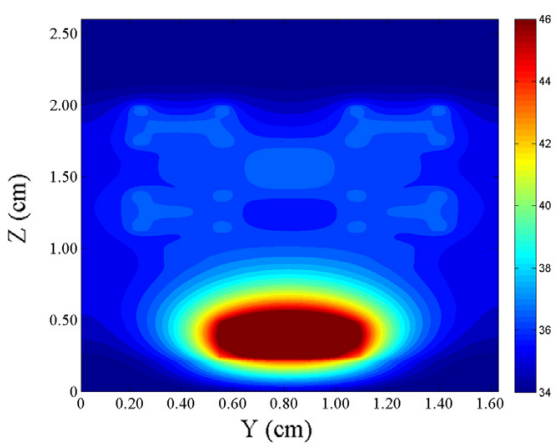

(e)

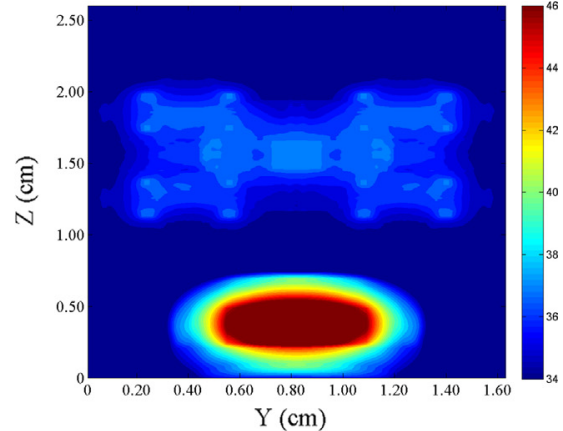

(c)

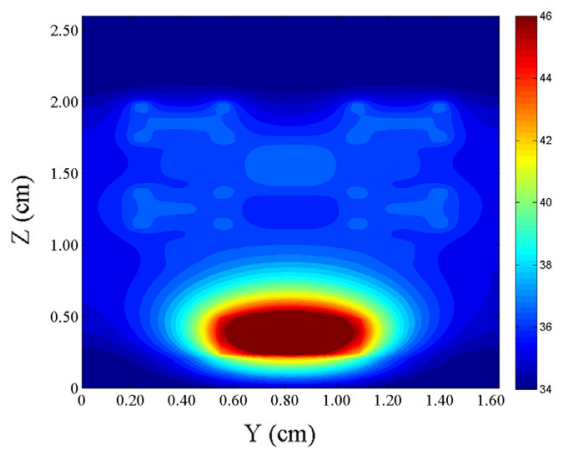

(f)

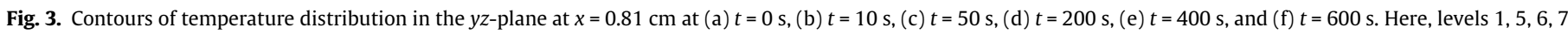
of the arterial system and the center of the tumor are visible.

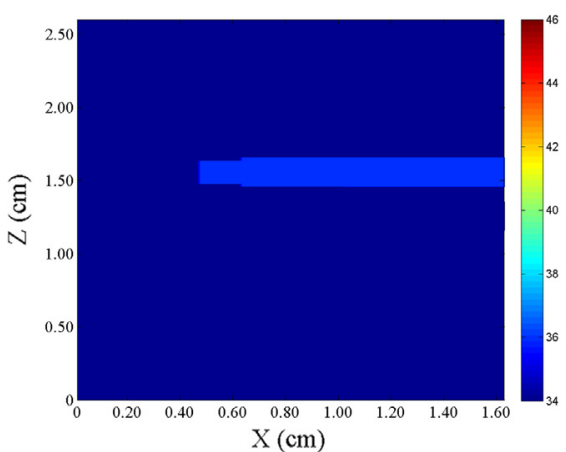

(a)

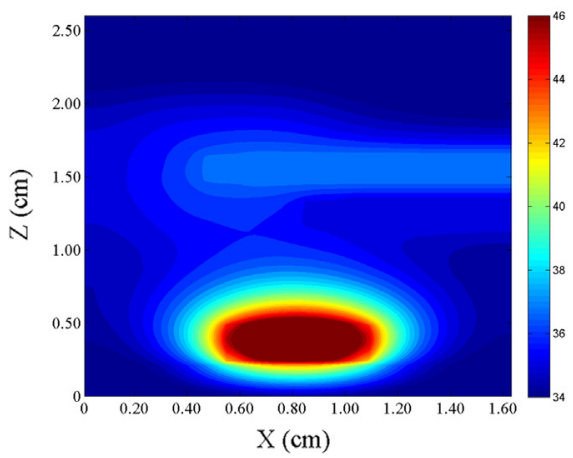

(d)

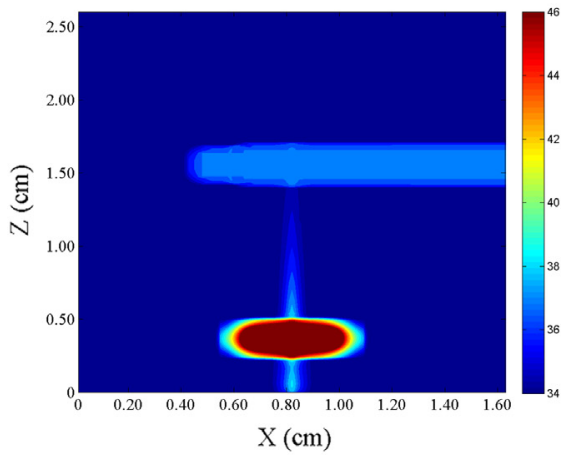

(b)

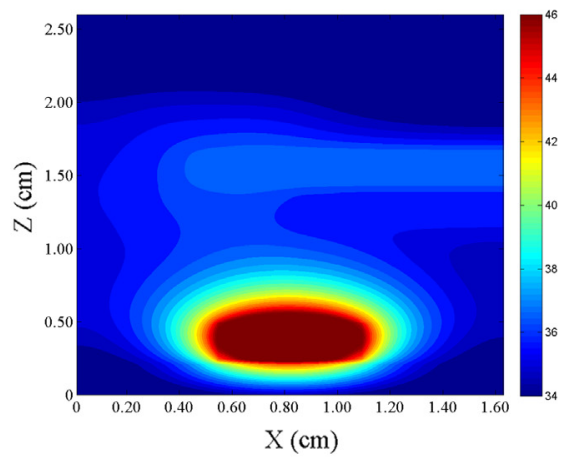

(e)

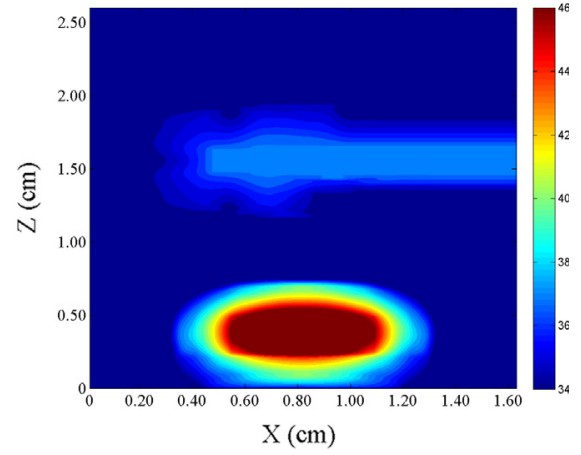

(c)

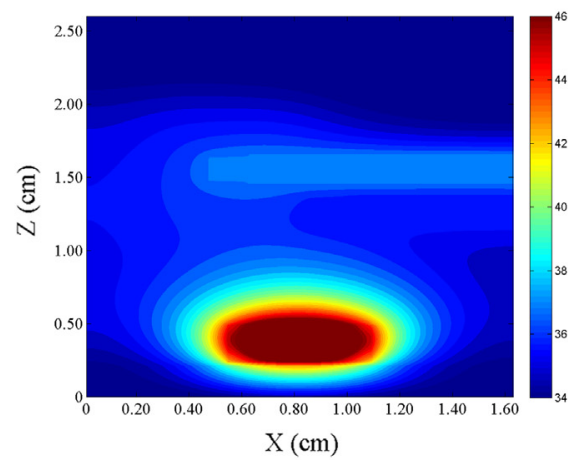

(f)

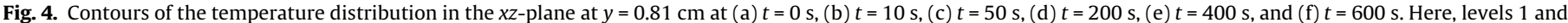
2 of the arterial system and the center of the tumor are visible. 
embedded in the tumor region, we optimized $P_{0}$ based on the algorithm described in the previous section with an initial value of $P_{0}$ as $1.295 \mathrm{~W} / \mathrm{cm}$ and the value of $\Delta P_{0}$ to be $1 \%$ of $P_{0}$. Fig. 2 shows $P_{0}$ and the least-squares sum versus iteration, respectively. It can be seen that $P_{0}$ is convergent to $1.601 \mathrm{~W} / \mathrm{cm}$. We then used this convergent value of $P_{0}$ to compute the temperature distribution in the 3-D skin structure.

Fig. 3 shows the temperature distribution in the cross-section of the tumor center at $x=0.81 \mathrm{~cm}$, where levels $1,5-7$ of the arterial system are visible. At $t=10 \mathrm{~s}$, the laser just turned off the first time in the simulation. As seen in Fig. 3(b), the temperature in the core tumor region (around $0.61 \mathrm{~cm} \leqslant y \leqslant 1.01 \mathrm{~cm}$ ) rises over $46{ }^{\circ} \mathrm{C}$ with the maximum $54^{\circ} \mathrm{C}$ in the center of the tumor, while the rest of the region being below $42^{\circ} \mathrm{C}$. This is because the nanoshells absorb heat quickly, resulting in the temperature rise promptly in the core tumor region. Also, it can be seen that the laser does not heat up much for the rest region due to the lower intensity of the laser. Furthermore, the blood vessels (levels 1, 57) are clearly visible because the arterial component of the vascular system is set to have a blood temperature of $37^{\circ} \mathrm{C}$. At $t=50 \mathrm{~s}$ as shown in Fig. 3(c), the temperature in the entire tumor $(0.54 \mathrm{~cm} \leqslant y \leqslant 1.08 \mathrm{~cm})$ is in between 45 and $54{ }^{\circ} \mathrm{C}$ while the normal tissue is below $42{ }^{\circ} \mathrm{C}$. The heat diffusion from the core to the entire tumor and the surrounding is seen. At $t=200 \mathrm{~s}$ as shown

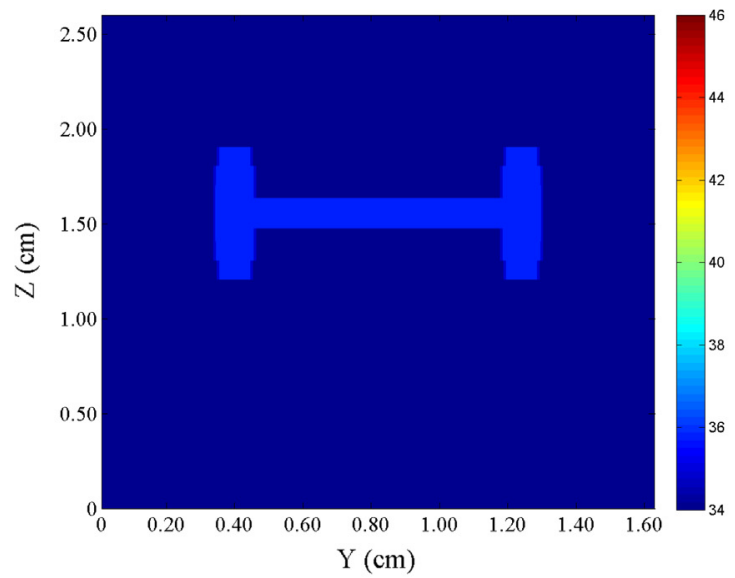

(a)

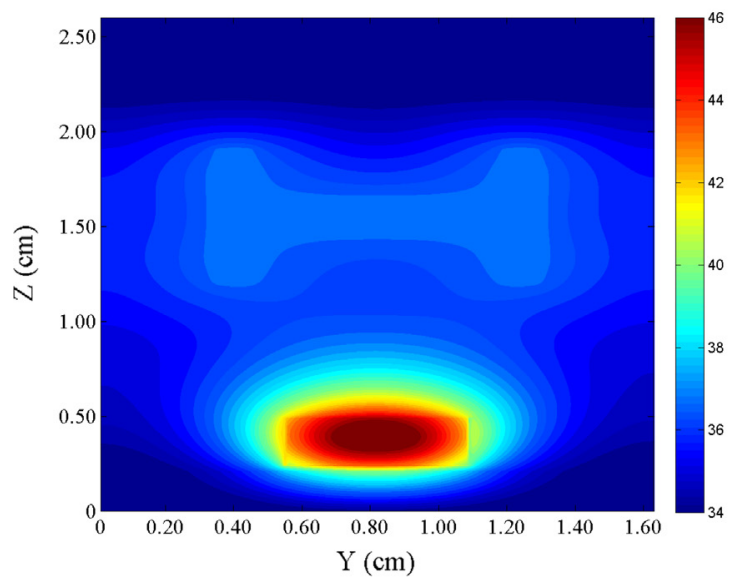

(c) in Fig. 4(d), the entire tumor keeps the temperature over 44$46{ }^{\circ} \mathrm{C}$ and the normal tissue is below $42{ }^{\circ} \mathrm{C}$. It can be seen that the overall elevated temperature field slightly expands due to the heat diffusion, as compared with that in Fig. 3(c). At $t=400 \mathrm{~s}$ as shown in Fig. 3(e), it can be seen that the tumor still keeps the temperature over $46{ }^{\circ} \mathrm{C}$ and the normal tissue is below $42{ }^{\circ} \mathrm{C}$. At $t=600 \mathrm{~s}$ as shown in Fig. 3(f), the contour shows slightly lower temperature levels on the edges of the tumor because the laser is turned on and off. Due to the symmetricity of the tumor about the center, similar results can be seen in Fig. 4 for the crosssection of the tumor center at $y=0.81 \mathrm{~cm}$, where level 1 of the artery is visible. In summary, numerical results from Figs. 3 and 4 indicate that our method can control laser heating of the tumor (target temperatures of $42-54{ }^{\circ} \mathrm{C}$ ) and, on the other hand, keep the temperatures of the normal tissue surrounding the tumor low enough to not damage the normal tissue, which meets the objective of hyperthermia. It should be noted that the center of the tumor's desired temperature level is $50-54{ }^{\circ} \mathrm{C}$ so that the temperature in the entire tumor is elevated to the hyperthermia level and the center of the tumor enters the necrosis temperature range (temperatures greater than $50^{\circ} \mathrm{C}$ ).

Fig. 5 shows the temperature distribution in the cross-section of the tumor lateral side at $x=0.54 \mathrm{~cm}$, where levels $2-4$ of the arterial system are visible. At $t=200 \mathrm{~s}$ as shown in Fig. 5(b), the center

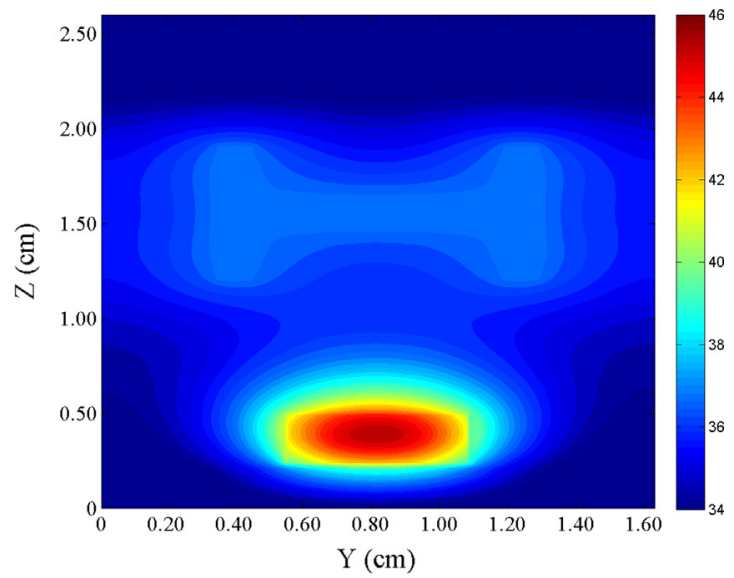

(b)

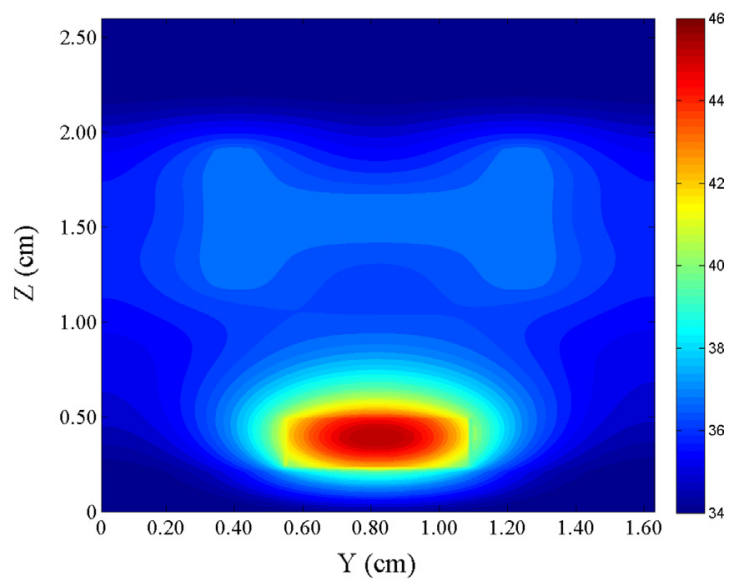

(d)

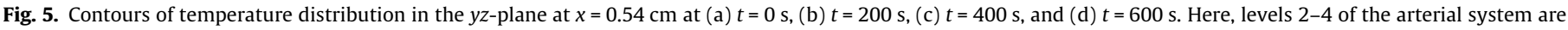
visible. 


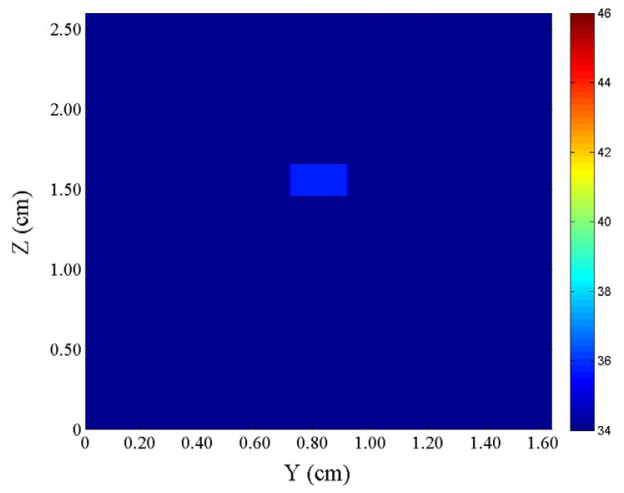

(a)

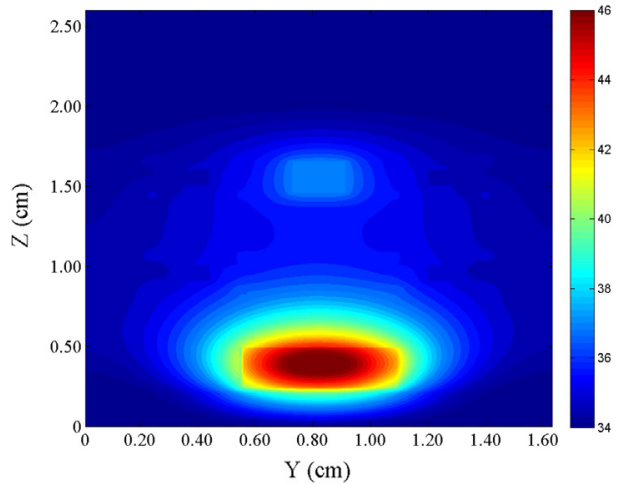

(c)

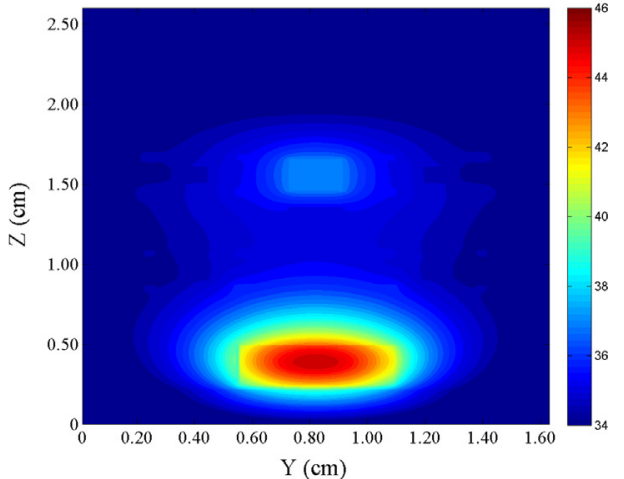

(b)

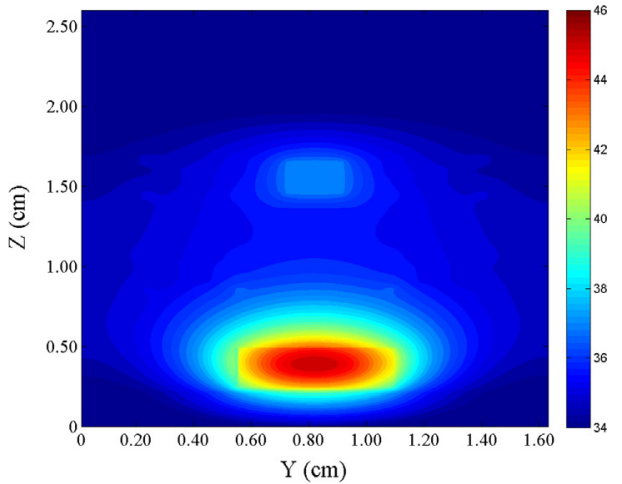

(d)

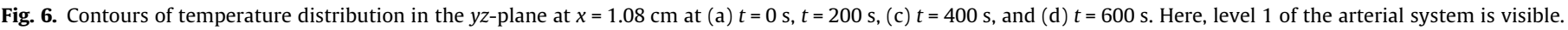

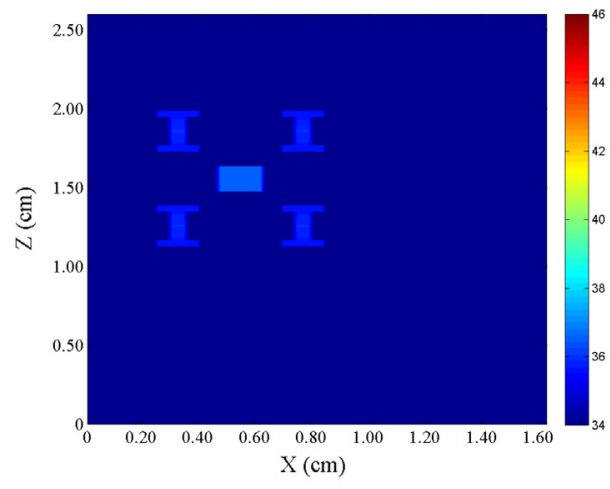

(a)

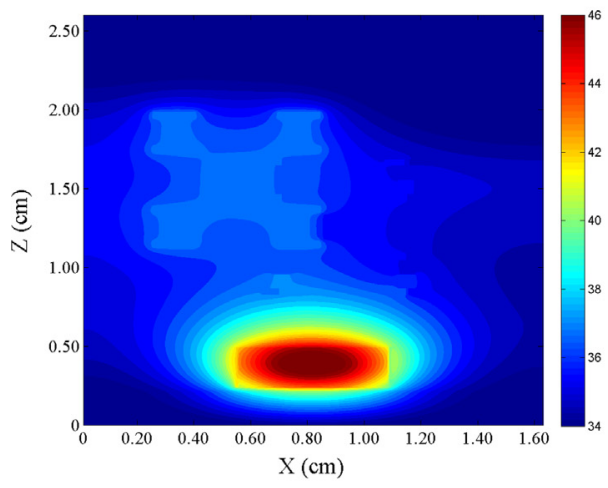

(c)

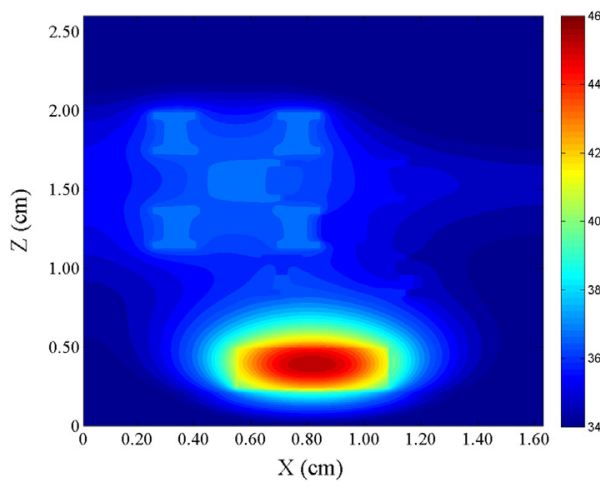

(b)

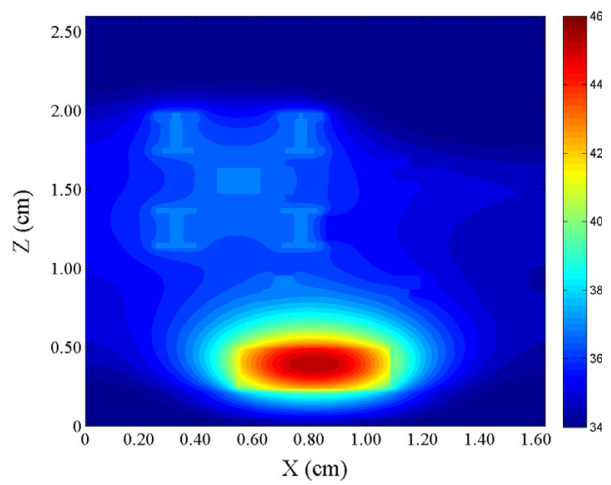

(d)

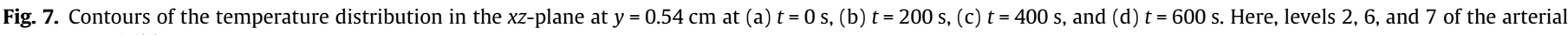
system are visible. 


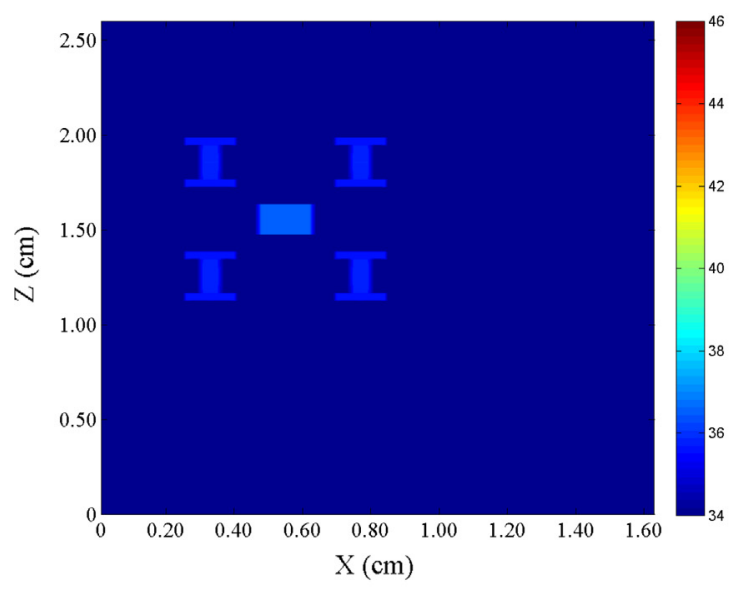

(a)

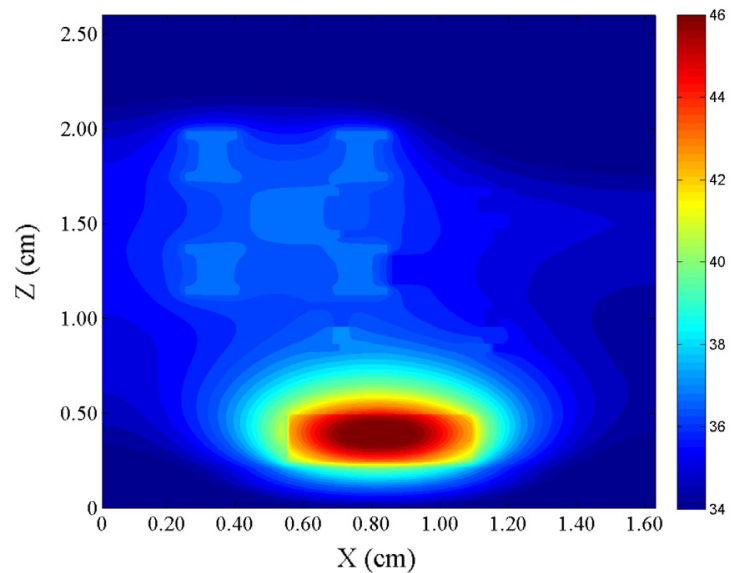

(c)

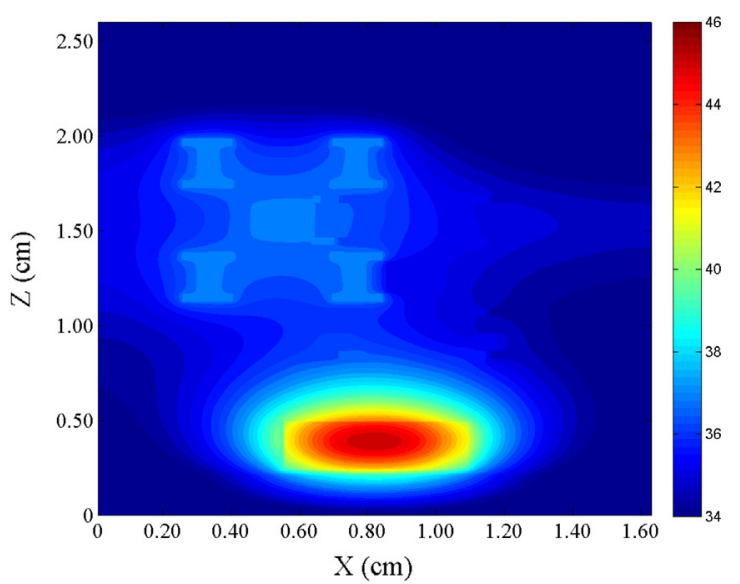

(b)

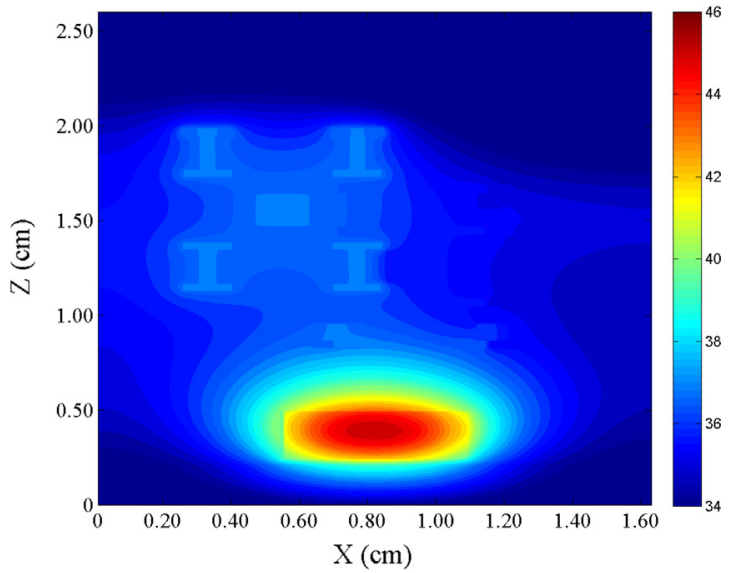

(d)

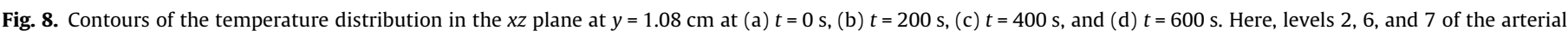
system are visible.

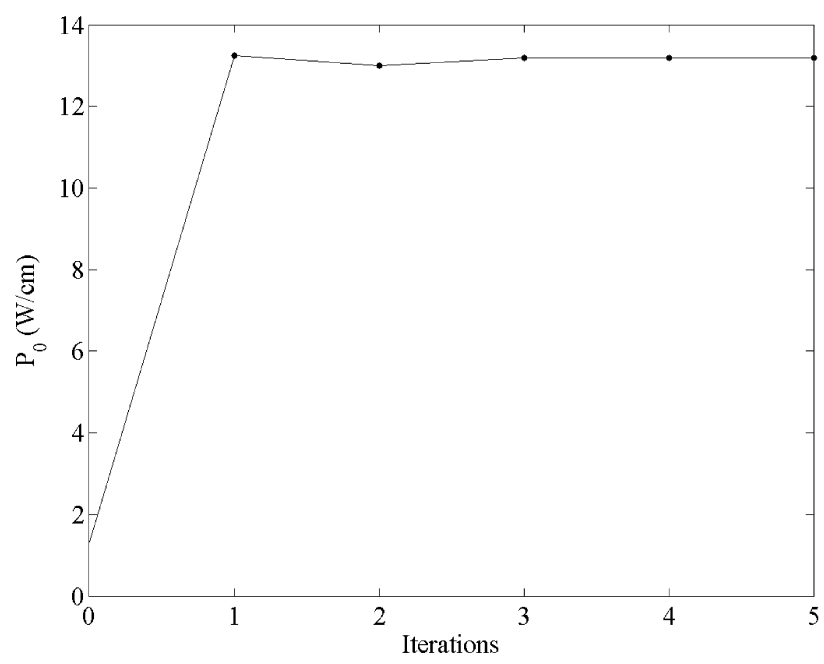

(a)

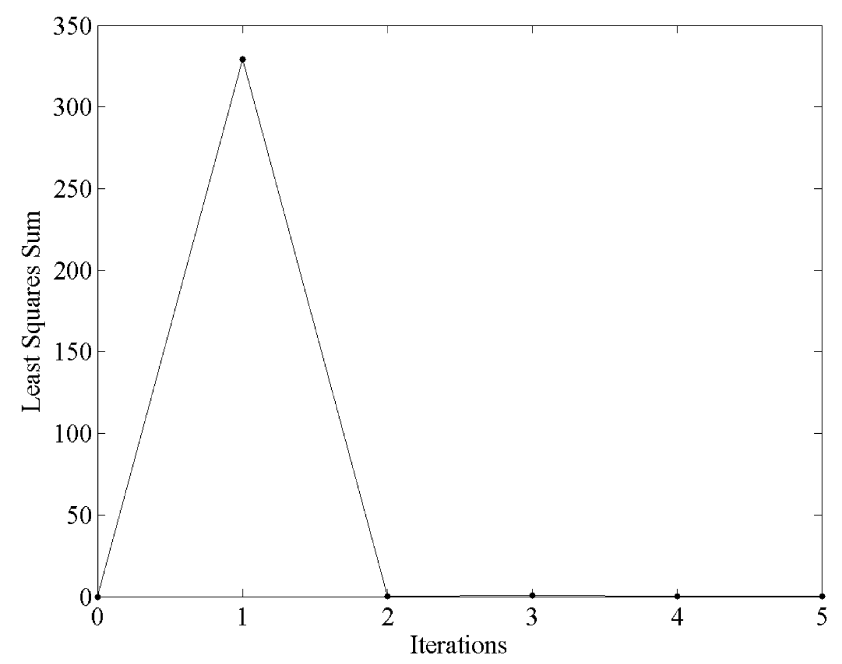

(b)

Fig. 9. Number of iterations versus (a) laser intensity $\left(P_{0}\right)$, and (b) least squares sum, $S\left(P_{0}\right)$. 


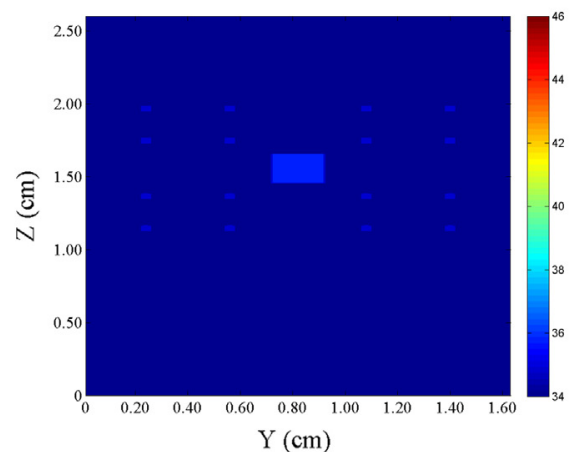

(a)

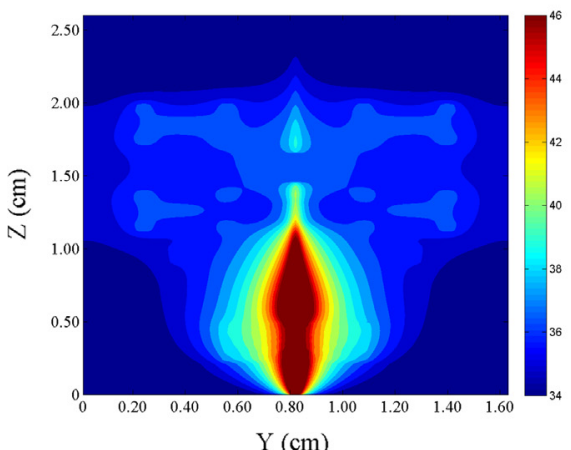

(d)

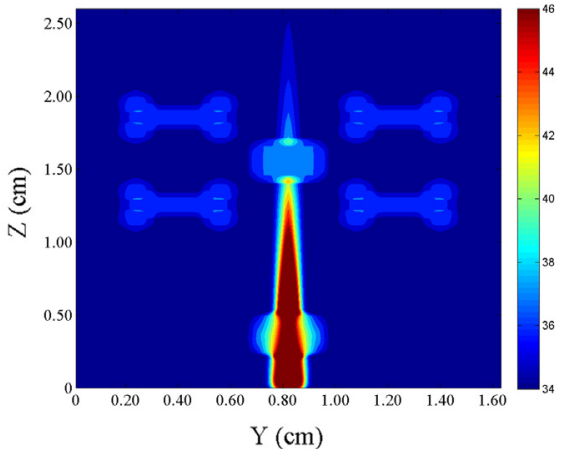

(b)

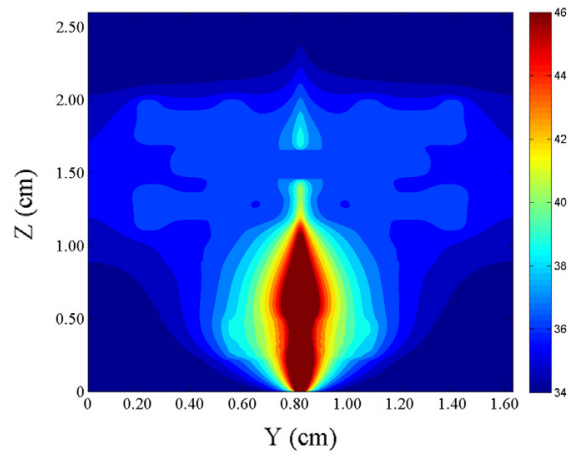

(e)

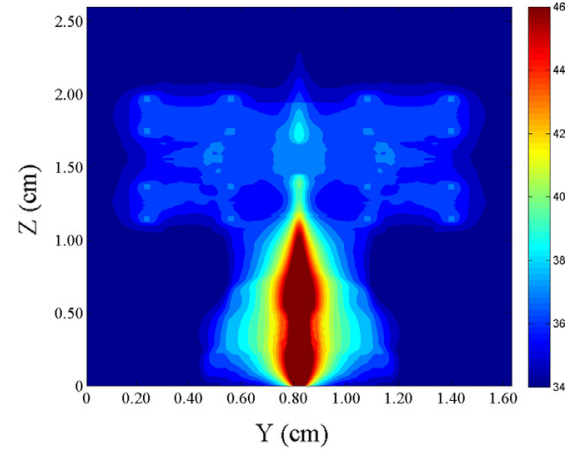

(c)

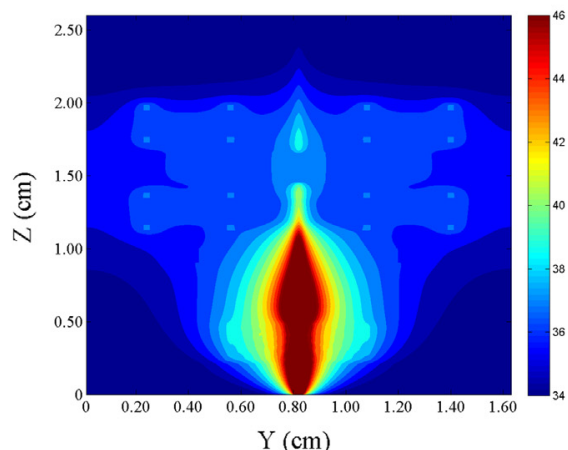

(f)

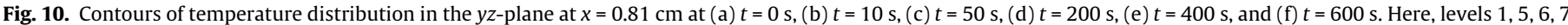
of the arterial system and the center of the tumor are visible.

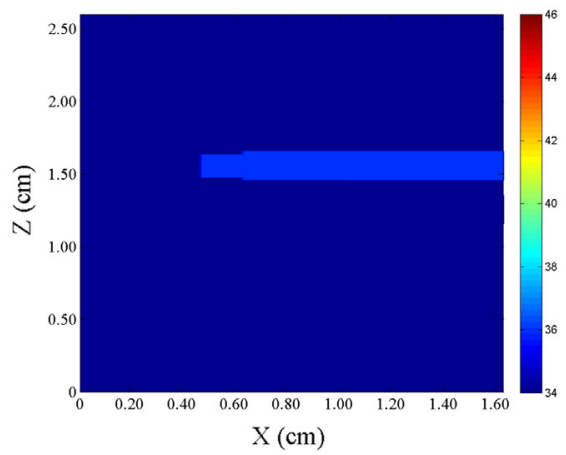

(a)

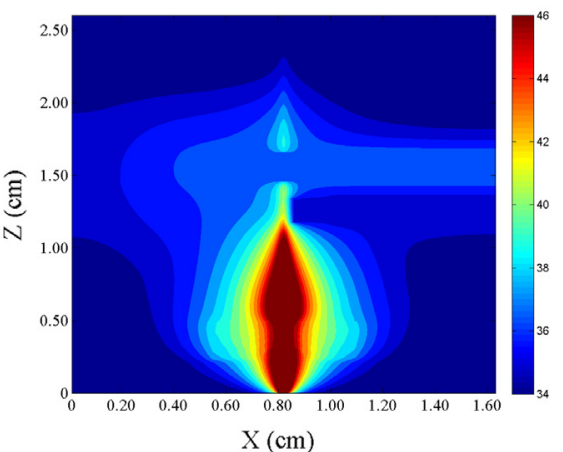

(d)

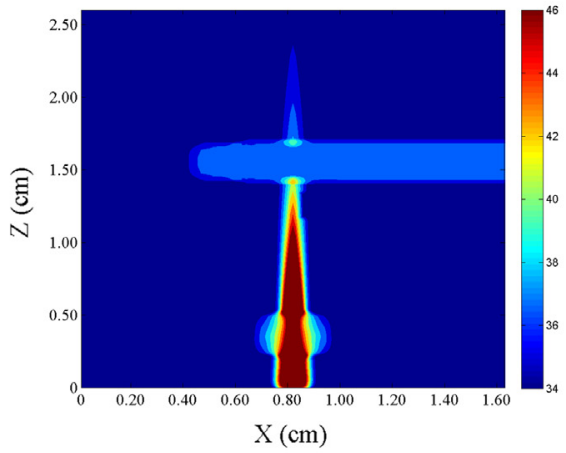

(b)

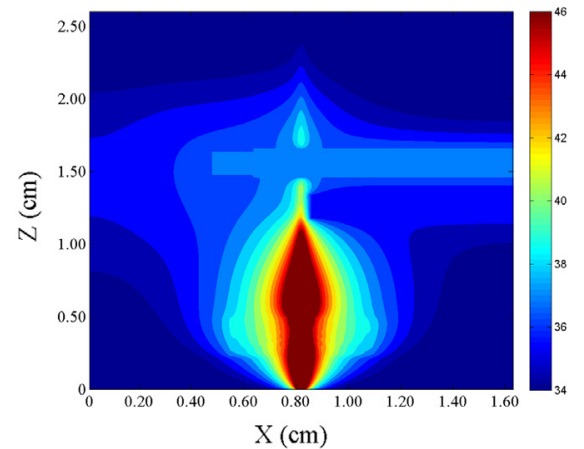

(e)

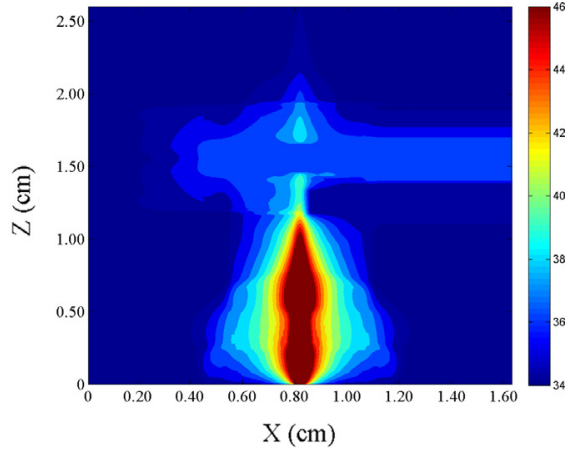

(c)

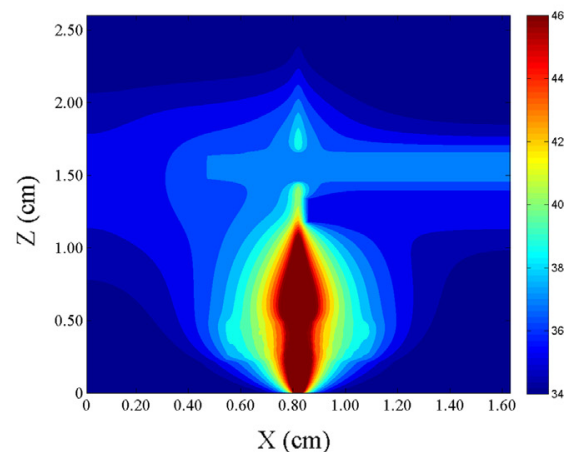

(f)

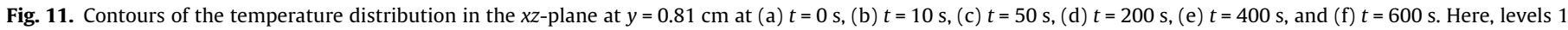
and 2 of the arterial system and the center of the tumor are visible. 


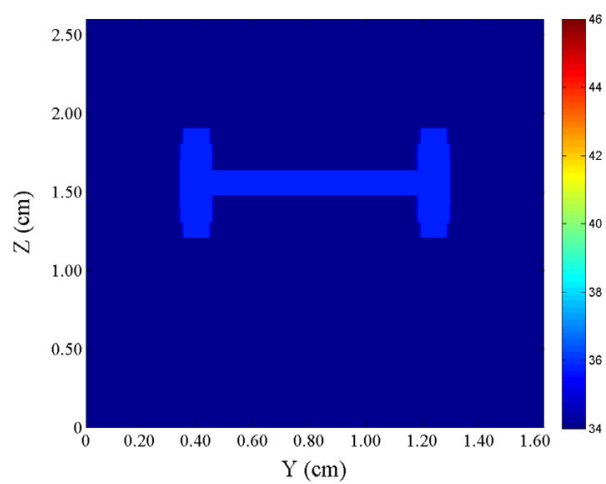

(a)

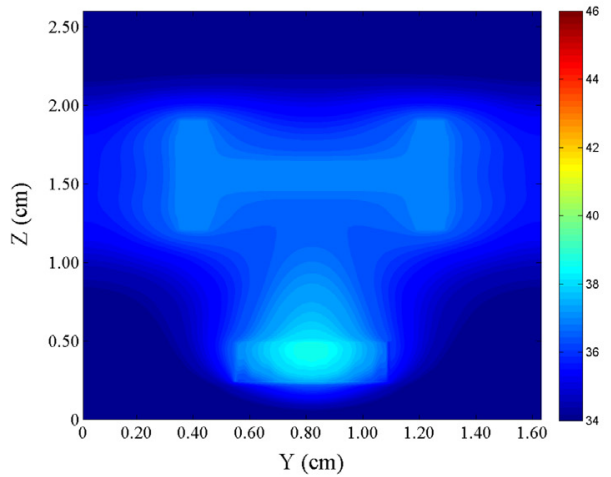

(c)

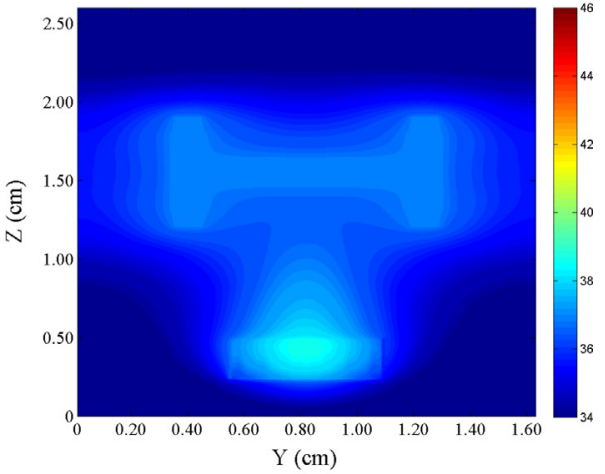

(b)

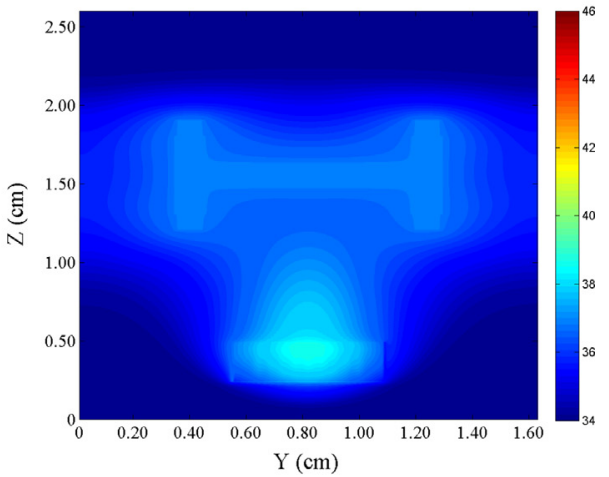

(d)

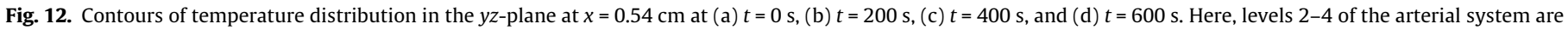
visible.

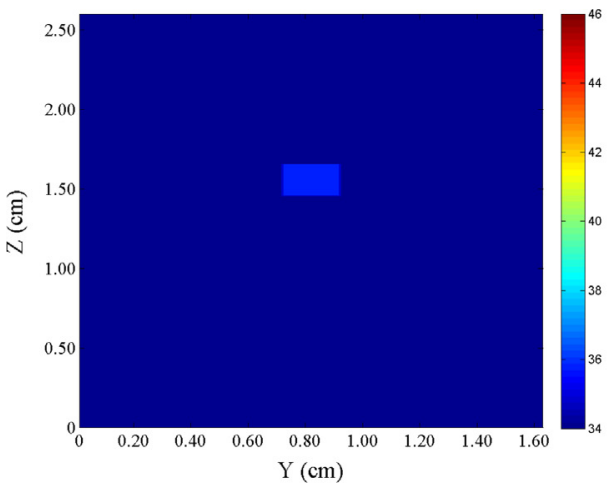

(a)

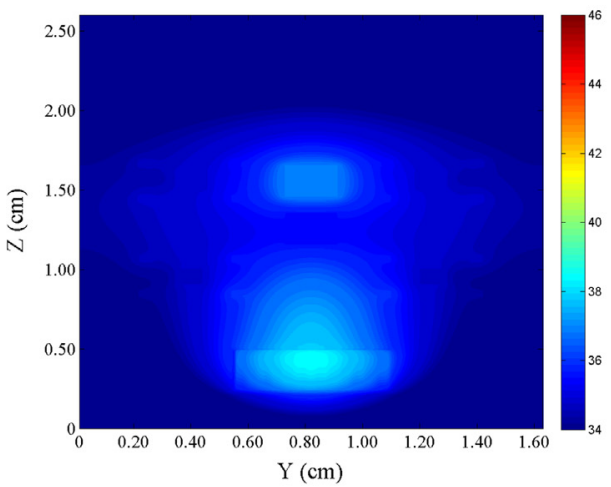

(c)

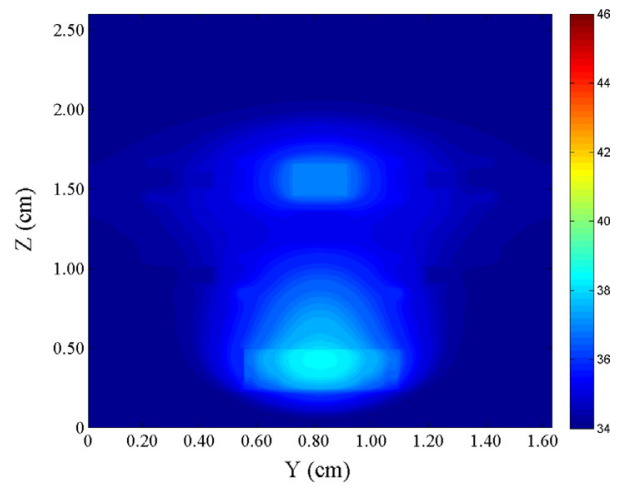

(b)

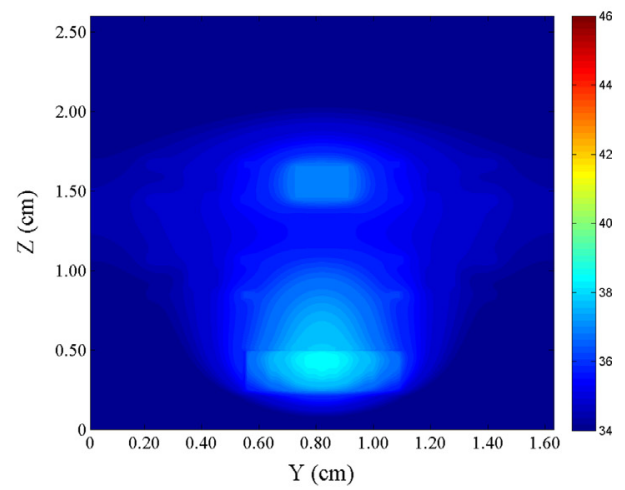

(d)

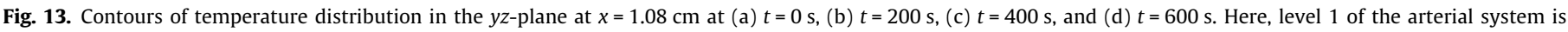
visible. 
of the tumor side has risen to around $44{ }^{\circ} \mathrm{C}$ and the surrounding region in the tumor is within the temperature range of $38-42{ }^{\circ} \mathrm{C}$. On the other hand, the rest of the normal tissue is below $38^{\circ} \mathrm{C}$. Furthermore, the blood vessels (levels 2-4) are clearly visible because the arterial component of the vascular system has a blood temperature of $37^{\circ} \mathrm{C}$. At $t=400 \mathrm{~s}$ as shown in Fig. 5(c), the temperature at the center of the lateral face has risen to around $45^{\circ} \mathrm{C}$, while the immediate surrounding region is between 41 and $44^{\circ} \mathrm{C}$. As a result of the diffusing of heat from the center of the tumor, the area showing elevated temperatures has slightly expanded. At $t=600 \mathrm{~s}$ as shown in Fig. 5(d), the contour shows slightly lower temperature levels than those compared with the contours at $t=400 \mathrm{~s}$. Similar results can be seen in Figs. $6-8$ for the crosssections of other three tumor lateral sides with various branches of the vascular network. Results from these figures confirm again that our method can control laser heating of the tumor (target temperatures over $42{ }^{\circ} \mathrm{C}$ ) and keep the temperatures of the normal tissue surrounding the tumor low enough to not damage the normal tissue.

For the study without nanoshells, again we optimized $P_{0}$ based on the algorithm described in the previous section with an initial value of $P_{0}$ as $1.295 \mathrm{~W} / \mathrm{cm}$ and the value of $\Delta P_{0}$ to be $1 \%$ of $P_{0}$. Fig. 9 shows $P_{0}$ and the least-squares sum versus iteration, respectively. It can be seen that $P_{0}$ is convergent to $13.193 \mathrm{~W} / \mathrm{cm}$. Compared with Fig. 2, we can see that without nanoshells, a larger laser power is needed in order to achieve the same criterion as the nanoshell case.

Fig. 10 shows the temperature distribution in the cross-section of the tumor center at $x=0.81 \mathrm{~cm}$, where levels $1,5-7$ of the arterial system are visible. At $t=10 \mathrm{~s}$ as shown in Fig. 10(b), after the initial heating of the center of the tumor has occurred and the laser has turned off, the center of the tumor is at $54{ }^{\circ} \mathrm{C}$, while areas that are directly above and below the tumor are ranging from 60 to $70{ }^{\circ} \mathrm{C}$ due to lower diffusivity and higher conductivity than the tumor region itself. The core tumor region $(0.71 \mathrm{~cm} \leqslant y \leqslant 0.9 \mathrm{~cm})$ is between 37 and $54{ }^{\circ} \mathrm{C}$ and the rest of the region not affected by the laser is below $37^{\circ} \mathrm{C}$. At $t=50 \mathrm{~s}$ as shown in Fig. 10 (c), the elevated temperature field has expanded laterally in the tumor and surrounding regions. The temperature in the center of the tumor is between 50 and $54^{\circ} \mathrm{C}$ while the regions directly above and below the tumor are at necrosis-inducing temperatures (60$\left.65{ }^{\circ} \mathrm{C}\right)$. At the same time, the rest of the tumor region $(0.54 \mathrm{~cm} \leqslant y \leqslant 1.08 \mathrm{~cm})$ is between 38 and $41{ }^{\circ} \mathrm{C}$ and the rest of the normal tissue unaffected by the laser is below $38^{\circ} \mathrm{C}$. At $t=200 \mathrm{~s}$ as shown in Fig. 10(d), the center of the tumor and surrounding regions are in similar temperature fields as Fig. 10(c).

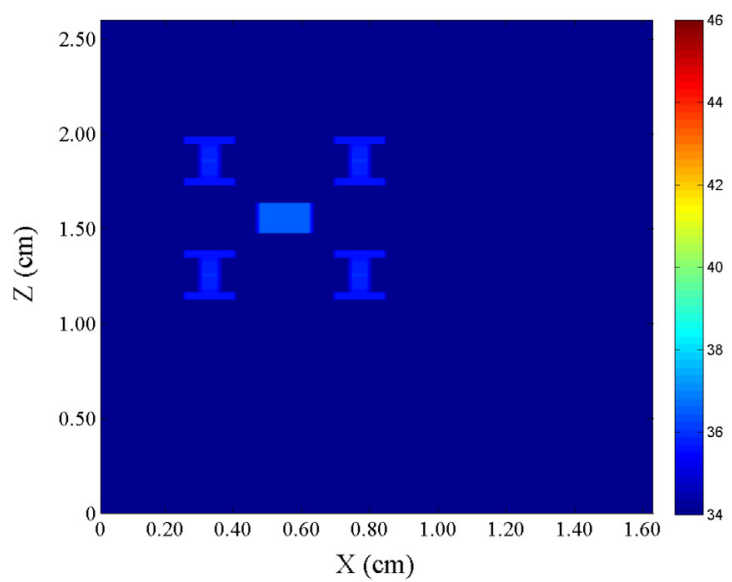

(a)

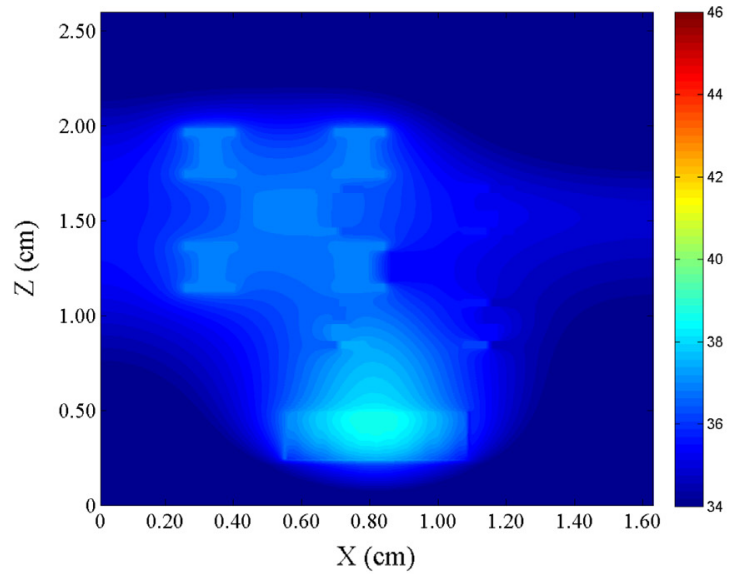

(c)

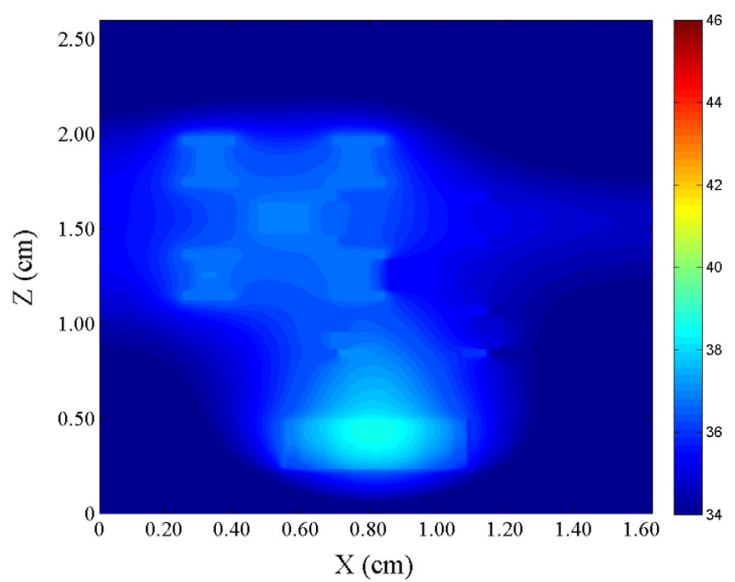

(b)

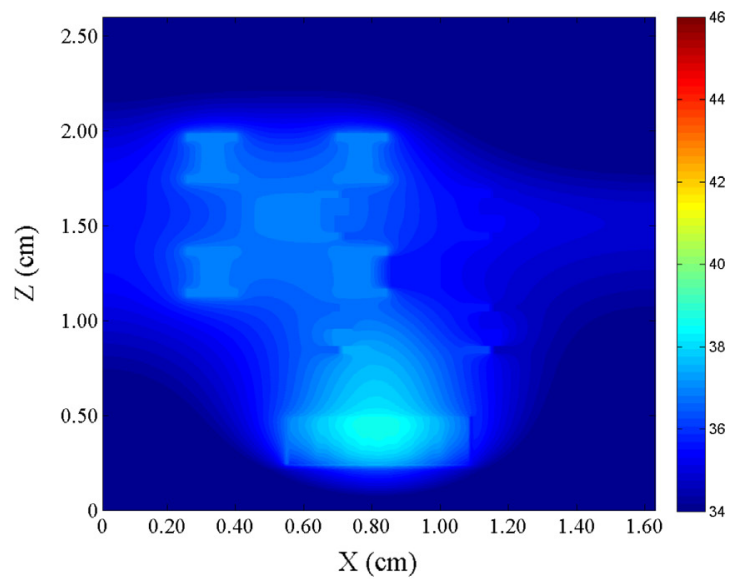

(d)

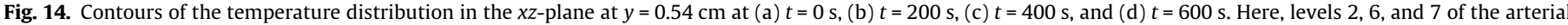
system are visible. 
At $t=400 \mathrm{~s}$ and $t=600 \mathrm{~s}$ as shown in Fig. 10(d) and (e), respectively, the temperature fields are at similar levels throughout the contour as Fig. 10(d). Similar results can be seen in Fig. 11 for the cross-section of the tumor center at $y=0.81 \mathrm{~cm}$, where level 1 of the artery is visible. From our computation, we found that our method can control laser heating, however, due to the diffusivity of the tumor and lack of nanoshells, the laser turns on and off at a high frequency. In comparing the laser intensity to the case with the nanoshells, the laser intensity is much higher which results in more heat being deposited into the system. From these two figures, it can be seen that the laser is heating up not only the center of the tumor, but is also heating up some normal tissue to levels that can cause damage.

Fig. 12 shows the temperature distribution in the cross-section of the tumor lateral side at $x=0.54 \mathrm{~cm}$, where levels $2-4$ of the arterial system are visible. At $t=200 \mathrm{~s}$ as shown in Fig. 12(b), the center of the tumor lateral side has risen to around $39^{\circ} \mathrm{C}$ and the surrounding region is below $38^{\circ} \mathrm{C}$. Furthermore, the blood vessels (levels 2-4) are clearly visible because the arterial component of the vascular system has a blood temperature of $37^{\circ} \mathrm{C}$. At $t=400 \mathrm{~s}$ and $t=600 \mathrm{~s}$ as shown in Figs. 12(c) and (d), respectively,

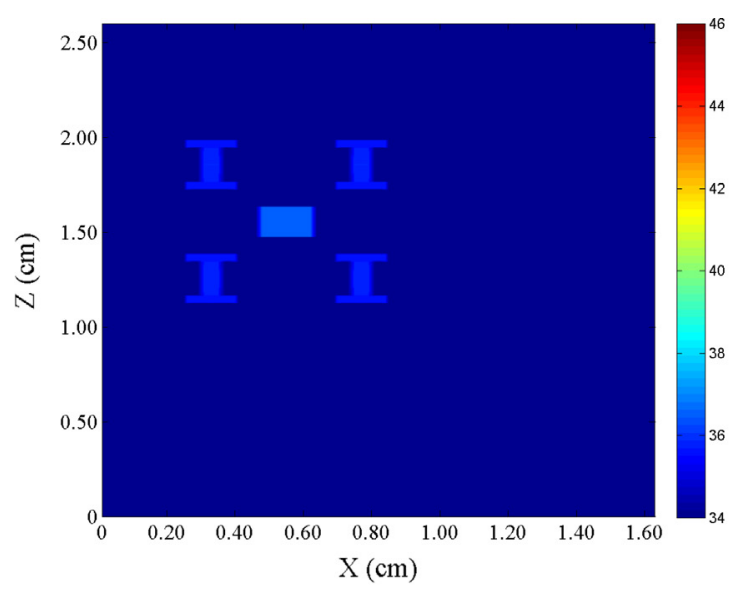

(a)

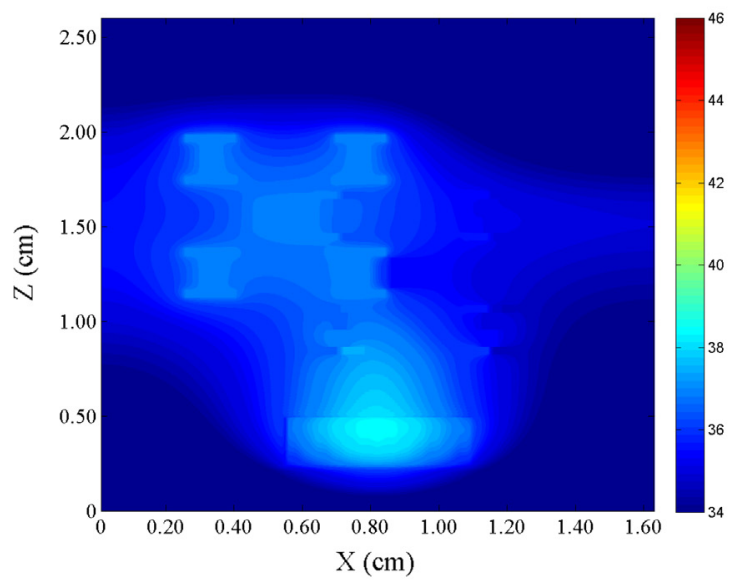

(c) the temperature field has slightly expanded due to the diffusing heat from the center of the tumor with temperatures remaining similar to Fig. 12(b). Similar results can be seen in Figs. 13-15 for the cross-sections of other three tumor lateral sides with various branches of the vascular network being visible. Results show that, without nanoshells, the heat is transferred at such a high rate mainly along the thickness direction, resulting in not only failing to heat up the entire tumor region over target temperatures of $42-46{ }^{\circ} \mathrm{C}$, but also damaging the normal tissue above and below the tumor.

In comparison between Figs. 3-8 and Figs. 10-15, we conclude that using the nanoshells has an advantage to heat up a tumor region quickly while keeping the surrounding healthy tissue from being damaged.

Because the present scheme, Eqs. (19) and (20), is unconditionally stable and the Richardson iteration, Eqs. (30) and (31), is convergent (implying that the numerical solution is convergent to the analytical solution according to the theory related to the finite difference method [61]), we finally tested the grid-independence of our algorithm for stability. Fig. 16 shows four temperature profiles selected at $t=50 \mathrm{~s}$ by using three different meshes of

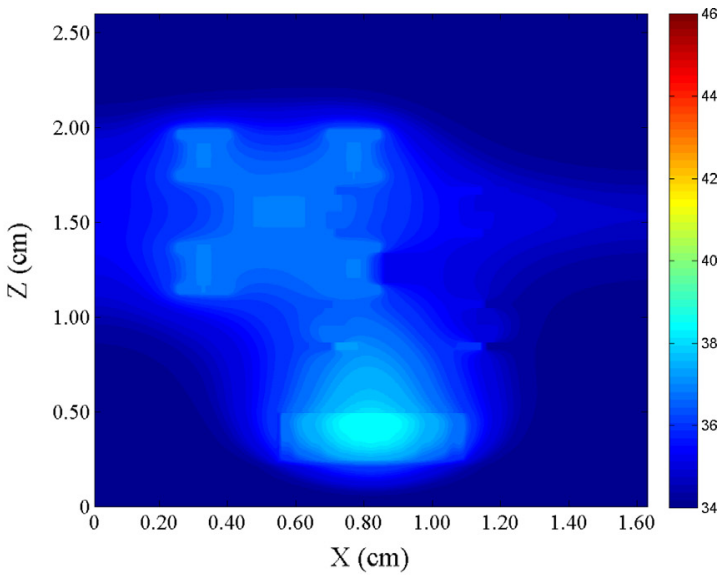

(b)

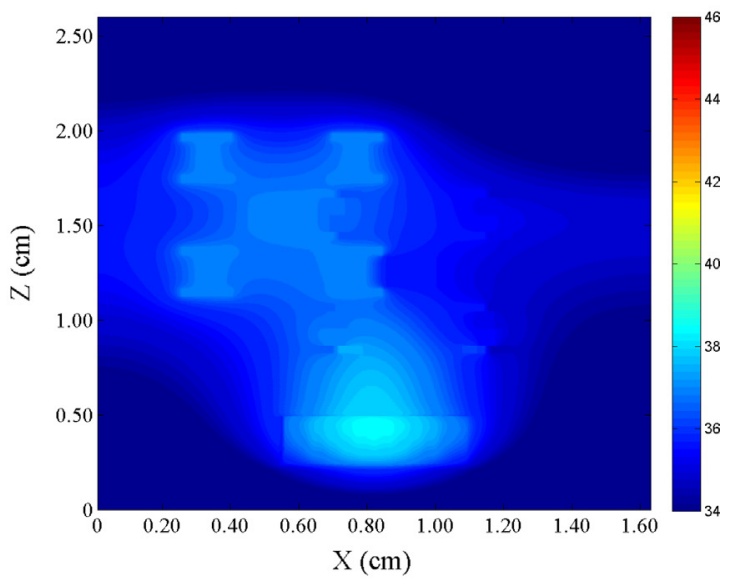

(d)

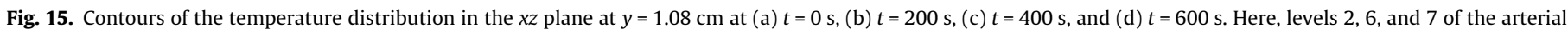
system are visible. 


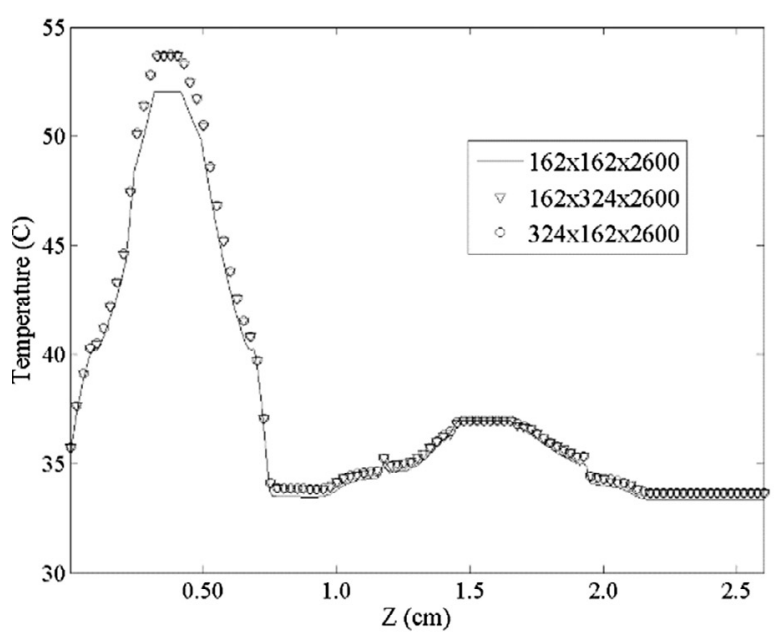

(a)

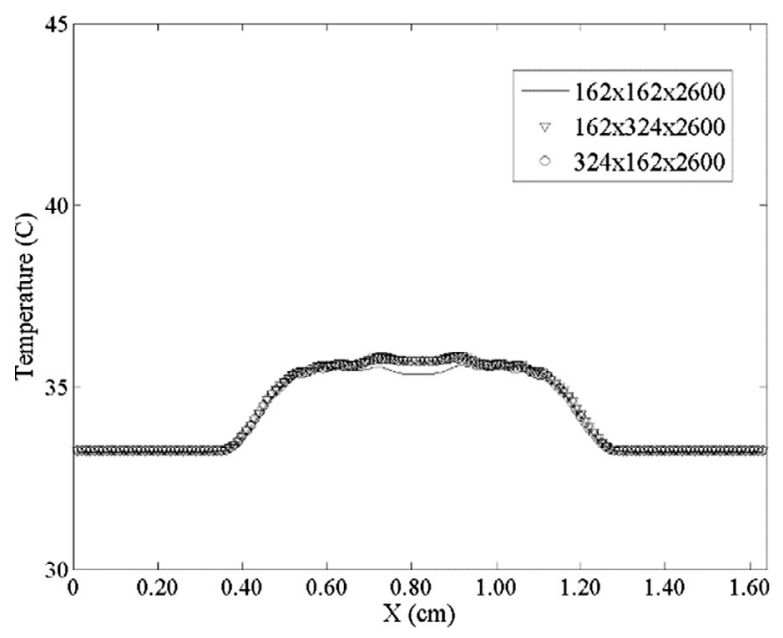

(c)

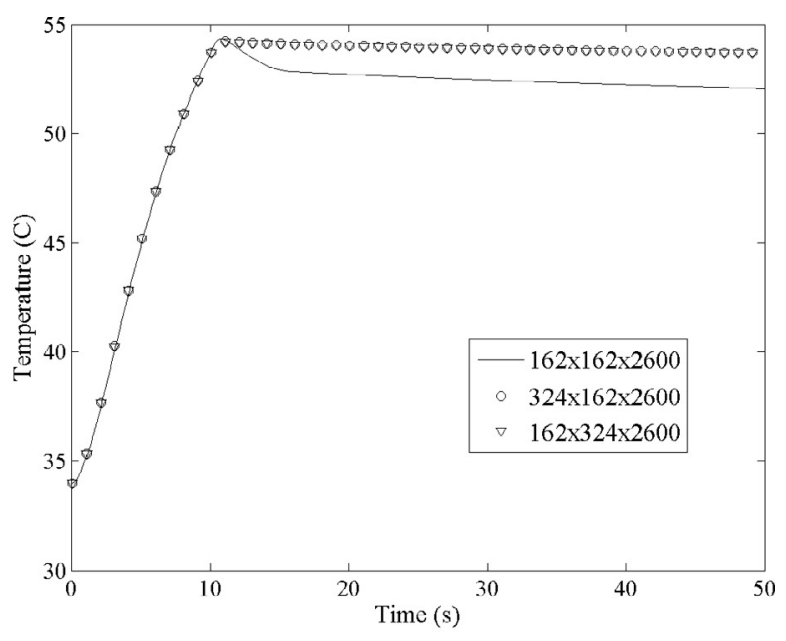

(b)

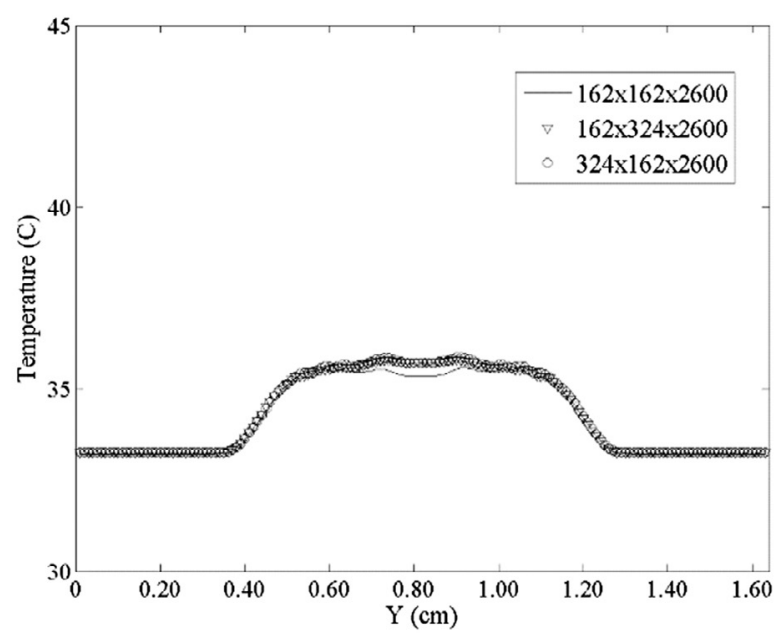

(d)

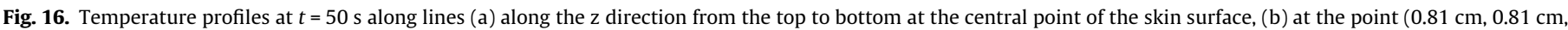
$0.365 \mathrm{~cm}$ ) over time, (c) $y=0.81 \mathrm{~cm}$, and (d) $x=0.81 \mathrm{~cm}$ on the surface of the skin.

$162 \times 162 \times 2600,162 \times 324 \times 2600$, and $324 \times 162 \times 2600$ with a time step $\Delta t=0.1 \mathrm{~s}$ in the computation. Fig. 17 shows four temperature profiles selected at $t=150 \mathrm{~s}$ by using three different time steps of $0.1 \mathrm{~s}, 0.15 \mathrm{~s}$, and $0.2 \mathrm{~s}$ with a mesh of $162 \times 162 \times 2600$ in the computation. It can be seen from these two figures that there are no significant differences among these solutions, implying that our scheme is grid-independent.

\section{Conclusion}

We have developed a numerical method for obtaining an optimal temperature distribution in a 3-D triple layered rectangular skin structure with an embedded countercurrent vascular network comprised of seven-level blood vessels, arteries and veins. The mathematical model takes into account the relatively large thermal relaxation time of biological tissue with the effects of golden nanoshells that were injected in a tumor region appearing in the subcutaneous region. The dimensions and blood flow rates are determined based on the constructal design of multi-scale tree-shaped heat exchangers. Numerical results show that the tumor tissue, with an optimized laser intensity and golden nanoshells, can be heated and maintained above $42^{\circ} \mathrm{C}$ while the surrounding healthy tissue is kept from being damaged.

Further study will be focus on the use of the dual-phase lagging equation as a new modified bioheat transfer equation as considered by other researchers [19,54,55,63-71], where the relaxation times associated with both heat flux and the temperature gradients are considered. In particular, we have noticed that the overall tissue can be considered to be a porous medium consisting of the vascular region and the extravascular region. As a result, Eq. (5) for the temperature field can be revised to a two-equation porous model, which leads to a dual-phase lagging equation [19,54,6870]. In addition, we will consider irregular geometries for a skin structure and tumor region where the finite element method may be included. Such research may provide an useful tool for optimizing laser irradiation to kill the tumor while keeping the damage to the surrounding healthy tissue to a minimum during the hyperthermia cancer treatment. 


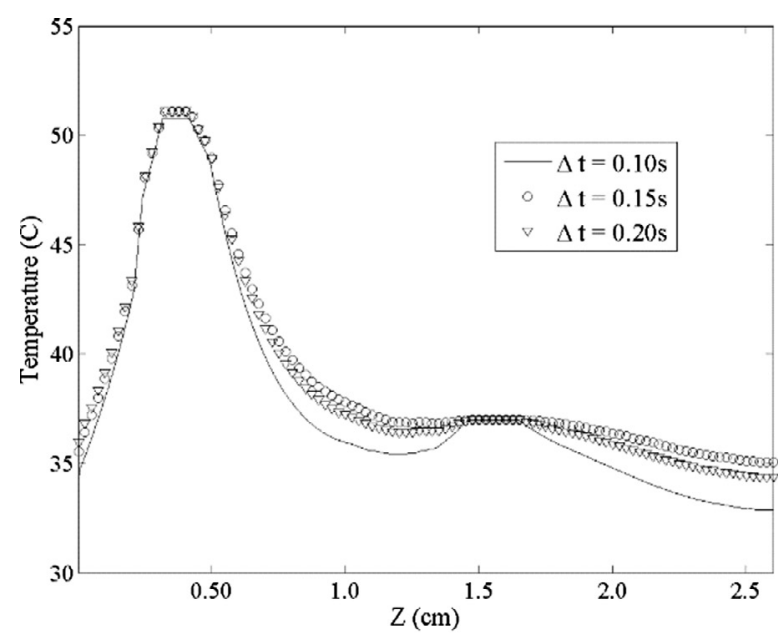

(a)

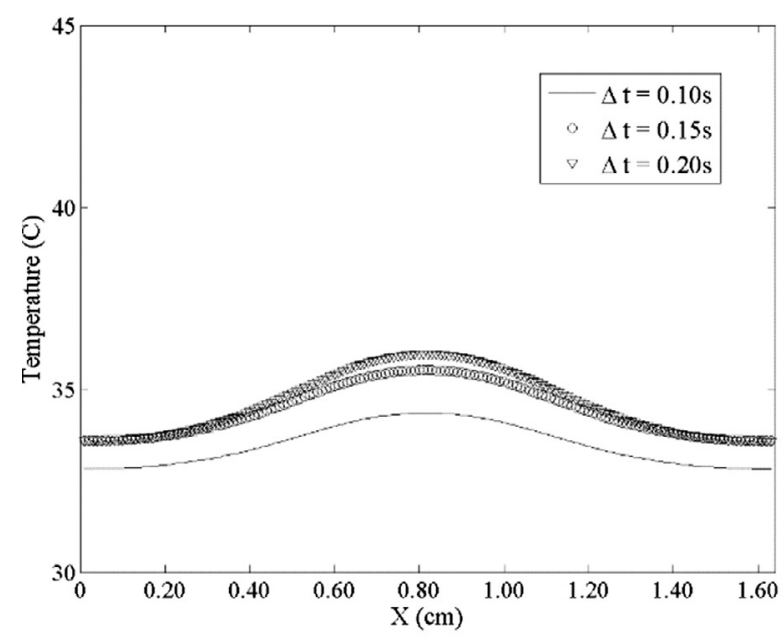

(c)

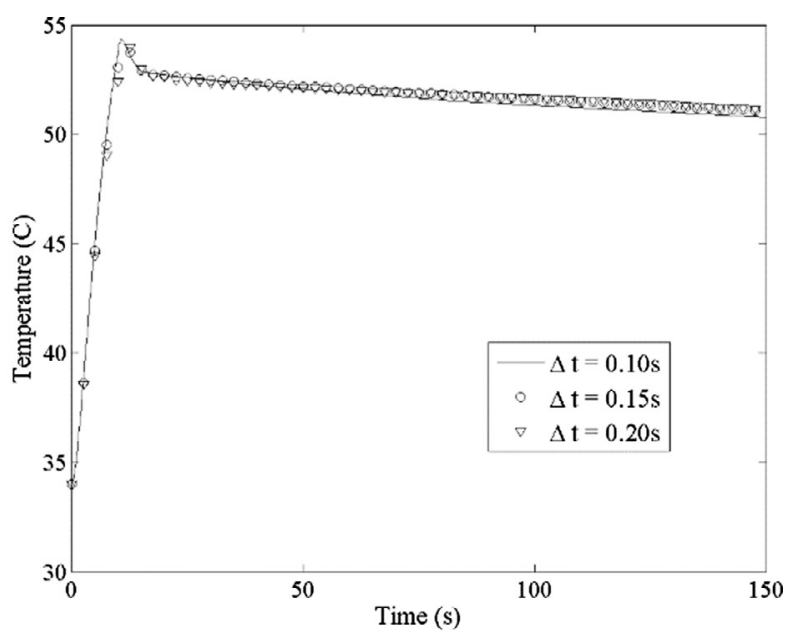

(b)

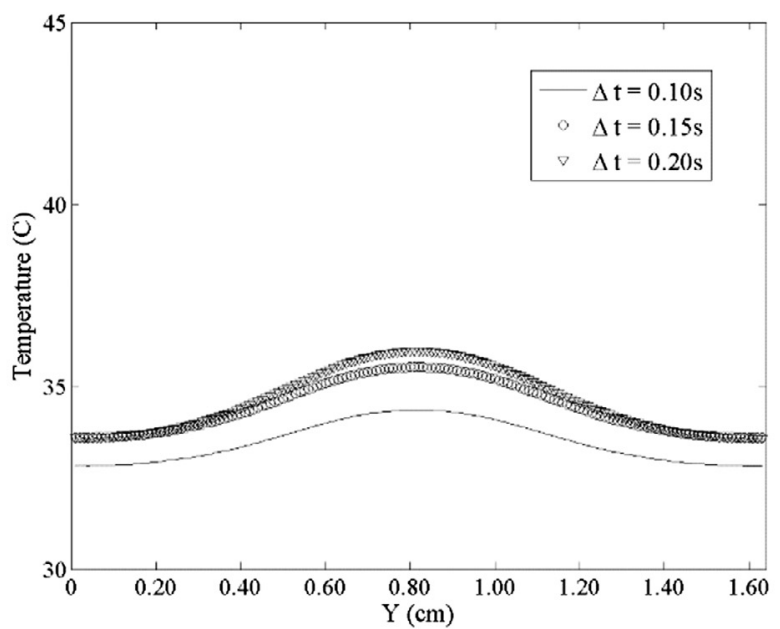

(d)

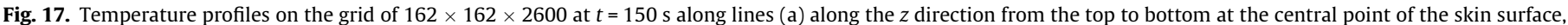
(b) at the point $(0.81 \mathrm{~cm}, 0.81 \mathrm{~cm}, 0.365 \mathrm{~cm})$ over time, (c) $y=0.81 \mathrm{~cm}$, and (d) $x=0.81 \mathrm{~cm}$ on the surface of the skin.

\section{Acknowledgement}

The authors would like to express their gratitude to the anonymous reviewers for their valuable suggestions for enhancing the quality of the manuscript.

\section{Appendix A. Appendix}

\section{A.1. Nanoshell heating equations}

In the development of the $u^{\prime \prime \prime}$ term, it is observed that $[23,24]$

$u^{\prime \prime \prime}=-\frac{d q_{R \lambda}^{\prime \prime}}{d z}$

where the spectral radiative heat flux, $q_{R \lambda}(z)$, is the sum of the collimated radiation, $q_{c_{\lambda}}(z)$, and the heat generation caused by diffuse radiation, $q_{d \lambda}(z)$. The collimated radiation is defined as

$q_{c \lambda}(z)=\left(1-\rho_{\lambda}\right) q_{i n}^{\prime \prime} e^{\frac{-\alpha_{g} z}{\mu_{c}}}$,

where $\alpha_{g}$ is the absorptivity of the golden nanoshells. The diffuse radiation is defined as $q_{d \lambda}(z)=C_{1} e^{\xi_{1} \beta_{\text {tot- }-\lambda} z}+C_{2} e^{-\xi_{1} \beta_{\text {tot }-\lambda} z}+B_{1} e^{-\beta_{\text {tot }-\lambda} z}$,

where $C_{1}$ and $C_{2}$ are calculated by using the values that are defined by Eq. (A3) in the following manner:

$$
\left[\begin{array}{l}
C_{1} \\
C_{2}
\end{array}\right]=\left[\begin{array}{ll}
B_{2} & B_{3} \\
B_{6} & B_{7}
\end{array}\right]^{-1}\left[\begin{array}{l}
B_{4} B_{1}+B_{5} \\
B_{8} B_{1}+B_{9}
\end{array}\right] .
$$

From above, $B_{1}$ through $B_{9}$ are defined as

$B_{1}=-\frac{1}{\mu_{c}} \frac{\omega_{\lambda} q_{i n, \lambda}^{\prime \prime}}{\frac{1}{\mu_{c}}-\xi_{1}^{2}}, \quad B_{2}=2-\frac{\varepsilon_{\lambda}}{\left(2-\varepsilon_{\lambda}\right)\left(1-\omega_{\lambda}\right)} \xi_{1}$,

$B_{3}=2+\frac{\varepsilon_{\lambda}}{\left(2-\varepsilon_{\lambda}\right)\left(1-\omega_{\lambda}\right)} \xi_{1}$,

$B_{4}=-\left(2+\frac{\varepsilon_{\lambda}}{\left(2-\varepsilon_{\lambda}\right)\left(1-\omega_{\lambda}\right)} \frac{1}{\mu_{c}}\right)$,

$B_{5}=-\frac{\varepsilon_{\lambda}}{\left(2-\varepsilon_{\lambda}\right)} \frac{\omega_{\lambda}}{\left(1-\omega_{\lambda}\right)} q_{i n, \lambda}^{\prime \prime}$,

$B_{6}=-\left(2 e^{\xi_{1} \tau_{L \lambda}}+\frac{\varepsilon_{\lambda}}{\left(2-\varepsilon_{\lambda}\right)\left(1-\omega_{\lambda}\right)} \xi_{1} e^{\xi_{1} \tau_{L \lambda}}\right)$, 


$$
\begin{aligned}
& B_{7}=-2 e^{-\xi_{1} \tau_{L \lambda}}+\frac{\varepsilon_{\lambda}}{\left(2-\varepsilon_{\lambda}\right)\left(1-\omega_{\lambda}\right)} \xi_{1} e^{-\xi_{1} \tau_{L \lambda}}, \\
& B_{8}=2 e^{-\frac{\tau_{L \lambda}}{\mu_{c}}}-\frac{\varepsilon_{\lambda}}{\left(2-\varepsilon_{\lambda}\right)\left(1-\omega_{\lambda}\right)} \frac{e^{-\frac{\tau_{L \lambda}}{\mu_{c}}}}{\mu_{c}}
\end{aligned}
$$

$$
B_{9}=-\frac{\varepsilon_{\lambda}}{\left(2-\varepsilon_{\lambda}\right)} \frac{\omega_{\lambda}}{\left(1-\omega_{\lambda}\right)} q_{i n, \lambda}^{\prime \prime} e^{-\frac{\tau_{L \lambda}}{\mu_{c}}}, \quad \xi_{1}=\sqrt{3\left(1-\omega_{\lambda}\right)} .
$$

From Eqs. (A1)-(A5), we obtain $\varepsilon_{\lambda}, \tau_{L \lambda}, \mu_{c}, q_{i n, \lambda}^{\prime \prime}, \rho_{\lambda}, \omega_{\text {tot- } \lambda}$. Here, $\varepsilon_{\lambda}$ represents the proportion of incoming light that is transmitted through the boundary surface; it is equivalent to $1-\rho_{\lambda}(0)$ and $1-\rho_{\lambda}\left(\tau_{L \lambda}\right)$ at the entry and exit boundaries, respectively. For our study, as in the study in [23], reflections at the boundaries are going to be minimal and insignificant resulting in $\rho_{\lambda}$ to be very small, thus all the $\rho_{\lambda}$ will be considered zero. From this assumption, we conclude that $\varepsilon_{\lambda}=1$.

Since $\rho_{\lambda}$ is very small, Eq. (A2) can be slightly changed to $q_{c \lambda}(z)=q_{i n, \lambda}^{\prime \prime} e^{\frac{-\alpha g z}{\mu_{c}}} . \omega_{\lambda}$ is the scattering albedo for the system, so equivalently $\omega_{\lambda}$ and $\omega_{\text {tot }-\lambda}$ are the same term, and is defined as $\omega_{\lambda}=\frac{\sigma_{s-\lambda}+\sigma_{\text {md }-\lambda}}{\beta_{\text {tot }-\lambda}} . \tau_{L \lambda}$ represents the optical length of the tumor region defined as $\tau_{L \lambda}=\beta_{\text {tot }-\lambda} L_{T}$.

The extinction coefficient is defined as $\beta_{m d}=k_{m d-\lambda}+\sigma_{m d-\lambda}$, where $k_{m d-\lambda}$ and $\sigma_{m d-\lambda}$ are the spectral absorption and scattering coefficients of the medium, respectively. However, for the tumor region, the extinction coefficient also has to take into account the nanoshells that are scattering and absorbing the laser. The extinction for such would be defined as $\beta_{\text {tot }-\lambda}=k_{m d-\lambda}+\sigma_{m d-\lambda}+k_{s-\lambda}+$ $\sigma_{s-\lambda}$, where $k_{s-\lambda}$ and $\sigma_{s-\lambda}$ are the spectral absorption and scattering coefficients of the nanoshells, respectively. $k_{s-\lambda}$ and $\sigma_{s-\lambda}$ are defined as $k_{s-\lambda}=\pi r_{o}^{2} Q_{k \lambda} N_{T}, \sigma_{s-\lambda}=\pi r_{0}^{2} Q_{\sigma \lambda} N_{T}$, where $r_{o}, Q_{\sigma \lambda}, Q_{k \lambda}$, and $N_{T}$ are the outer radius, spectral scattering efficiency, spectral absorption efficiency of the nanoshells, and the amount nanoshells per unit volume, respectively.

Finally, $\mu_{c}$ represents the angle of incidence, which is defined as $\mu_{c}=\cos (\theta)$ and $q_{i n, \lambda}^{\prime \prime}$ represents the heat flux entering the subcutaneous region and is defined as $q_{i n, \lambda}^{\prime \prime}=\frac{P_{0}}{\sqrt{2 \pi} \sigma} e^{-\alpha_{1} L_{1}-\alpha_{2} L_{2}}$.

\section{References}

[1] R.B. Roemer, E.G. Moros, K. Hynynen, A comparison of bioheat transfer and effective conductivity equation predictions to experimental hyperthermia datam Advances in Bioengineering, in: ASME Winter Annual Meeting, 1989, pp. $11-15$.

[2] C.T. Liauh, R.B. Roemer, A semilinear state and parameter estimation algorithm for inverse hyperthermia problems, J. Biomech. Eng. 115 (1993) 257-261.

[3] I. Chatterjee, R.E. Adams, Finite element thermal modelling of the human body under hyperthermia treatment for cancer, Int. J. Comput. Appl. Technol. 7 (1994) 151-159.

[4] H.W. Huang, C.L. Chan, R.B. Roemer, Analytical solutions of Pennes bio-heat transfer equation with a blood vessel, J. Biomech. Eng. 116 (1994) 208-212.

[5] H.W. Huang, Z.P. Chen, R.B. Roemer, A countercurrent vascular network model of heat transfer in tissues, J. Biomech. Eng. 118 (1996) 120-129.

[6] A. Payne, M. Mattingly, R.B. Roemer, E.P. Scott, A model for a thin layer phantom with application to hyperthermia cancer therapy, ASMEPUBLICATIONS-BED 42 (1999) 197-198.

[7] E. Majchrzak, B. Mochnacki, Numerical model of heat transfer between blood vessel and biological tissue, Comput. Assist. Mech. Eng. Sci. 6 (1999) 439-447.

[8] J. Liu, X. Chen, L.X. Xu, New thermal wave aspects on burn evaluation of skin subjected to instantaneous heating, IEEE Trans. Biomed. Eng. 46 (1999) 420428.

[9] J. Liu, Preliminary survey on the mechanisms of the wave-like behaviors of heat transfer in living tissues, Forsch. Ingenieurwes. 66 (2000) 1-10.

[10] J. Sun, A. Zhang, L.X. Xu, Evaluation of alternate cooling and heating for tumor treatment, Int. J. Heat Mass Transfer 51 (2008) 5478-5485.

[11] W. Dai, H. Yu, R. Nassar, A fourth-order compact finite-difference scheme for solving a 1-d Pennes' bioheat transfer equation in a triple-layered skin structure, Numer. Heat Transfer Part B 46 (2004) 447-461.

[12] L. Zhang, W. Dai, R. Nassar, A numerical method for obtaining an optimal temperature distribution in a 3-d triple-layered cylindrical skin structure embedded with a blood vessel, Numer. Heat Transfer Part A 49 (2006) 765784.
[13] X. Tang, W. Dai, R. Nassar, A. Bejan, Optimal temperature distribution in a three dimensional triple-layered skin structure embedded with artery and vein vasculature, Numer. Heat Transfer Part A 50 (2006) 809-834.

[14] X. Zeng, W. Dai, A. Bejan, Vascular countercurrent network for 3-d triplelayered skin structure with radiation heating, Numer. Heat Transfer Part A 57 (2010) 369-391.

[15] E. Majchrzak, B. Mochnacki, M. Dziewoński, M. Jasiński, Numerical modelling of hyperthermia and hypothermia processes, Adv. Mater. Res. 268 (2011) 257262.

[16] M. Jamil, E.Y.K. Ng, Ranking of parameters in bioheat transfer using Taguchi analysis, Int. J. Therm. Sci. 63 (2013) 15-21.

[17] A. Malek, G. Abbasi, Optimal control solution for Pennes' equation using strongly continuous semigroup, Kybernetika 50 (2014) 530-543.

[18] J. Randrianalisoa, L. Dombrovsky, W. Lipiniski, V. Timchenko, Effects of shortpulsed laser radiation transient heating of superficial human tissues, Int. J. Heat Mass Transfer 78 (2014) 488-497.

[19] E. Majchrzak, L. Turchan, J. Dziatkiewicz, Modeling of skin tissue heating using the generalized dual phase-lag equation, Arch. Mech. 67 (2015) 417-437.

[20] S. Kumar, A. Srivastava, Numerical investigation of the influence of pulsatile blood flow on temperature distribution within the body of laser-irradiated biological tissue phantoms, Int. J. Heat Mass Transfer 95 (2016) 662-677.

[21] S. SÂ anchez, O. Bautista, F. MÂ endez, Theoretical analysis of coupled thermal and denaturation processes in living tissues subject to a uniform surface heating condition, Int. J. Heat Mass Transfer 90 (2015) 728-742.

[22] W. Ma, W. Liu, M. Li, Analytical heat transfer model for targeted brain hypothermia, Int. J. Therm. Sci. 100 (2016) 66-74.

[23] I.K. Tjahjono, Y. Bayazitoglu, Near-infrared light heating of a slab by embedded nanoparticles, Int. J. Heat Mass Transfer 51 (2008) 1505-1515.

[24] J. Vera, Y. Bayazitoglu, Gold nanoshell density variation with laser power for induced hyperthermia, Int. J. Heat Mass Transfer 52 (2009) 564-573.

[25] J. Vera, Y. Bayazitoglu, A note on laser penetration in nanoshell deposited tissue, Int. J. Heat Mass Transfer 52 (2009) 3402-3406.

[26] X. Xu, A. Meade, Y. Bayazitoglu, Fluence rate distribution in laser-induced interstitial thermotherapy by mesh free collocation, Int. J. Heat Mass Transfer 53 (2010) 4017-4022.

[27] X. Xu, A. Meade, Y. Bayazitoglu, Numerical investigation of nanoparticle assisted laser-induced interstitial thermotherapy for tumor and cancer treatments, Lasers Med. Sci 26 (2011) 213-222.

[28] X. Xu, A. Meade, Y. Bayazitoglu, Feasibility of selective nanoparticle assisted photothermal treatment for an embedded liver tumor, Lasers Med. Sci 28 (2013) 1151-1157.

[29] W. Cai, T. Gao, H. Hong, J. Sun, Applications of gold nanoparticles in cancer nanotechnology, Nanotechnol. Sci. Appl. 1 (2008) 17-32.

[30] E. Lechtman, S. Mashouf, N. Chattopadhyay, B.M. Keller, P. Lai, Z. Cai, R.M. Reilly, J.P. Pignol, A monte carlo-based model of gold nanoparticle radiosensitization accounting for increased radiobiological effectiveness, Phys. Med. Biol. 58 (2013) 30-75.

[31] R. Singh, K. Das, S.C. Mishra, Laser-induced hyperthermia of nanoshell mediated vascularized tissue-a numerical study, J. Therm. Biol 44 (2014) 55-62.

[32] Y. Lin, S.J. McMahon, H. Paganetti, J. Schuemann, Biological modeling of gold nanoparticle enhanced radiotherapy for proton therapy, Phys. Med. Biol. 60 (2015) 41-49.

[33] M. Nabil, P. Decuzzi, P. Zunino, Modelling mass and heat transfer in nanobased cancer hyperthermia, Roy. Soc. Open Sci. 2 (2015) 150-447.

[34] A. Sazgarnia, N. Naghavi, H. Mehdizadeh, Z. Shahamat, Investigation of thermal distribution for pulsed laser radiation in cancer treatment with nanoparticlemediated hyperthermia, J. Therm. Biol 47 (2015) 32-41.

[35] Z. Liu, Y. Liu, Y. Chang, H.R. Seyf, A. Henry, A.L. Mattheyses, K. Yehl, Y. Zhang, Z Huang, K. Salaita, Nanoscale optomechanical actuators for controlling mechanotransduction in living cells, Nat. Methods 13 (2015) 143-146.

[36] L.T. Curtis, C.G. England, M. Wu, J. Lowengrub, H.B. Frieboes, An interdisciplinary computational/experimental approach to evaluate drugloaded gold nanoparticle tumor cytotoxicity, Nucleic Acids Res. 11 (2016) $197-216$.

[37] C. Orndorff, W. Dai, Numerical hyperthermia simulation for a 3-d triplelayered skin structure with embedded vascular countercurrent network and nanoparticles, Int. J. Heat Technol. 34 (2016) s179-s184.

[38] I.A. Lubashevsky, V.V. Gaïychuk, Analysis of the optimality principles responsible for vascular network architectonics, arXiv preprint adap-org/ 9909003, 1999.

[39] M.M. Chen, K.R. Holmes, Microvascular contributions in tissue heat transfer Ann. N.Y. Acad. Sci. 335 (1980) 137-150.

[40] J. Zhou, J. Liu, Numerical study on 3-d light and heat transport in biological tissues embedded with large blood vessels during laser-induced thermotherapy, Numer. Heat Transfer Part A 45 (2004) 415-449.

[41] A. Bejan, S. Lorente, Design with Constructal Theory, Wiley, Hoboken, 2008.

[42] M. Alalaimi, S. Lorente, W. Wechsatol, A. Bejan, The robustness of the permeability of constructal tree-shaped fissures, Int. J. Heat Mass Transfer 90 (2015) 259-265.

[43] A. Bejan, The tree of convective heat streams: its thermal insulation function and the predicted 3/4-power relation between body heat loss and body size, Int. J. Heat Mass Transfer 44 (2001) 699-704.

[44] A. Bejan, S. Lorente, Constructal theory of generation of configuration in nature and engineering, J. Appl. Phys. 100 (2006) 41-301. 
[45] L. Zhang, W. Dai, R. Nassar, A numerical method for optimizing laser power in the irradiation of a 3-d triple-layered cylindrical skin structure, Numer. Heat Transfer Part A 48 (2005) 21-41.

[46] H.W. Huang, Convective thermal model formulation of a three dimensional vascular system with simplified blood flow paths: temperature distributions during hyperthermia (MS thesis), University of Arizona, Tucson, AZ, 1992.

[47] W. Dai, A. Bejan, X. Tang, L. Zhang, R. Nassar, Optimal temperature distribution in a three dimensional triple-layered skin structure with embedded vasculature, J. Appl. Phys. 99 (2006) 104-702.

[48] Y. Lv, Z. Deng, J. Liu, 3-d numerical study on the induced heating effects of embedded micro/nanoparticles on human body subject to external medical electromagnetic field, IEEE Trans. NanoBiosci. 4 (2005) 284-294.

[49] E. Majchrzak, M. Paruch, Identification of electromagnetic field parameters assuring the cancer destruction during hyperthermia treatment, Inverse Probl. Sci. Eng. 19 (2011) 45-58.

[50] P. Warrier, A. Teja, Effect of particle size on the thermal conductivity of nanofluids containing metallic nanoparticles, Nanoscale Res. Lett. 6 (2011) 16.

51] H.R. Seyf, S.M. Rassoulinejad-Mousavi, An analytical study for fluid flow in porous media imbedded inside a channel with moving or stationary walls subjected to injection/suction, J. Fluids Eng. 133 (2011) 091203.

[52] S.M. Rassoulinejad-Mousavi, H.R. Seyf, S. Abbasbandy, Heat transfer through porous saturated channel with permeable walls using two-equation energy model, J. Porous Media 16 (2013) 241-254.

[53] D.C.M. Vyas, S. Kumar, A. Srivastava, Porous media based bio-heat transfer analysis on counter-current artery vein tissue phantoms: applications in photo thermal therapy, Int. J. Heat Mass Transfer 99 (2016) 122-140.

[54] Y. Zhang, Generalized dual-phase lag bioheat equations based on nonequilibrium heat transfer in living biological tissues, Int. J. Heat Mass Transfer 52 (2009) 4829-4834.

[55] T-C. Shih, T-L. Horng, H-W. Huang, K-C. Ju, T-C. Huang, P-Y. Chen, Y-J. Ho, W-L Lin, Numerical analysis of coupled effects of pulsatile blood flow and thermal relaxation time during thermal therapy, Int. J. Heat Mass Transfer 55 (2012) 3763-3773.

[56] J. Han, K.F. Jensen, Combined experimental and modeling studies of laser assisted chemical vapor deposition of copper from copper (i)hexiuoroacetylacetonate trimethylvinylsilane, J. Appl. Phys. 75 (1994) 2240 2250.

[57] R.L. Burden, J.D. Faires, Numerical Analysis, eighth ed., Thomson Brooks/Cole,
[58] W. Dai, H. Wang, P.M. Jordan, R.E. Mickens, A. Bejan, A mathematical model for skin burn injury induced by radiation heating, Int. J. Heat Mass Transfer 51 (2008) 5497-5510

[59] W. Dai, R. Nassar, A finite difference scheme for solving a three-dimensional heat transport equations in a thin film with microscale thickness, Int. J. Numer. Methods Eng. 50 (2001) 1665-1680.

[60] M.N. Ozisik, Heat Conduction, second ed., John Wiley \& Sons, 1993.

61] K.W. Morton, D.F. Mayers, Numerical Solution of Partial Differential Equations, Cambridge University Press, London, 1994.

[62] A. Phadnis, S. Kumar, A. Srivastava, Numerical investigation of thermal response of laser-irradiated biological tissue phantoms embedded with gold nanoshells, J. Therm. Biol. 61 (2016) 16-28.

[63] O.I. Craciunescu, S.K. Das, R.L. McCauley, T.V. Samulski, Hyperthermia induced 3d temperature distribution in a human sarcoma with tumor perfusion reconstructed using fractal interpolation functions, ASME-PUBLICATIONS-HTD 368 (2000) 59-66.

[64] K.C. Liu, H.T. Chen, Investigation for the dual phase lag behavior of bioheat transfer, Int. J. Therm. Sci. 49 (2010) 1138-1146.

[65] K.C. Liu, Y.N. Wang, Y.S. Chen, Investigation on the bio-heat transfer with the dual-phase-lag effect, Int. J. Therm. Sci. 58 (2012) 29-35.

[66] E. Majchrzak, Numerical solution of dual phase lag model of bioheat transfer using the general boundary element method, Comput. Model. Eng. Sci. 69 (2010) 43-60.

[67] A. Malek, Z.K. Bojdi, P.N.N. Golbarg, Solving fully three-dimensional microscale dual phase lag problem using mixed-collocation, finite difference discretization, J. Heat Transfer 134 (2012) 094501-094506.

[68] E. Majchrzak, L. Turchan, The general boundary element method for 3D dualphase lag model of bioheat transfer, Eng. Anal. Boundary Elem. 50 (2015) 7682.

[69] N. Afrin, J. Zhou, Y. Zhang, D.Y. Tzou, J.K. Chen, Numerical simulation of thermal damage to living biological tissues induced by laser irradiation based on a generalized dual phase lag model, Numer. Heat Transfer Part A 61 (2012) 483-501.

[70] D.Y. Tzou, Macro- to Microscale Heat Transfer: The Lagging Behavior, second ed., Wiley, 2014.

[71] S. Patidar, S. Kumar, A. Srivastava, S. Singh, Dual phase lag model-based thermal analysis of tissue phantoms using lattice Boltzmann method, Int. J. Therm. Sci. 103 (2016) 41-56. 